\title{
¡Del dicho al hecho! \\ Las luchas de las mujeres afrocolombianas en Medellín por la reivindicación de los derechos de las trabajadoras domésticas de Colombia
}

\author{
From the saying to the fact! The struggles of Afro-Colombian \\ women in Medellin to demand the rights of Colombian domestic \\ workers
}

\author{
Sandra Milena Muñoz Cañas \\ Centro de Estudios Sociales, Defens, Colombia. Magister en Derecho de la Universidad Pontificia Bolivariana- \\ Medellín, Colombia. \\ sandramilemu@gmail.com | https://orcid.org/0000-0002-5165-9791
}

Recibido: 25 de julio de 2019. Aprobado: 14 de enero de 2020

DOI: $10.25100 /$ lamanzanadeladiscordia.v14i2.8833

Artículo de investigación

Financiación o proveniencia del artículo: Este artículo da cuenta de los resultados de la investigación "Barriendo Invisibilidades" llevada a cabo en el año 2012 y que realizó la Escuela Nacional Sindical (ENS) y la Corporación Afrocolombiana Desarrollo Social y Cultural (CARABANTÚ), unión que se dio en el marco del convenio "Acciones estratégicas en investigación para la inclusión y fortalecimiento de la población afrodescendiente en Colombia" y contó con el apoyo del Centro de Solidaridad de la AFL-CIO en Colombia. Una versión anterior del escrito fue preparada por Corporación Afrocolombiana Desarrollo Social y Cultural (CARABANTÚ). La autora agradece los aportes de María Edith Morales Mosquera, Ph.D en Administración y Docente Universidad de Antioquia, en la preparación de este escrito, en lo referente a la descripción del enfoque étnico racial de la investigación.

¿Cómo citar este artículo? / How to quote this article?

Muñoz-Cañas, S. M. (2020). ¡Del dicho al hecho!

Las luchas de las mujeres afrocolombianas en Medellín por la reivindicación de los derechos de las trabajadoras domésticas de Colombia. La Manzana de la Discordia, 14(2), 119-155. doi:

10.25100/lamanzanadeladiscordia.v14i2.8833 


\title{
Resumen
}

El trabajo doméstico remunerado es una actividad que emplea a gran cantidad de mujeres afrocolombianas en la ciudad de Medellín, por asuntos históricos de esclavitud, migración, falta de oportunidades para estudiar, discriminación para acceder a otros empleos, entre otras situaciones. Esto ha permitido que otras personas, al tener quien cuide de sus hogares, hayan podido realizar sus proyectos de vida. Sin embargo, resulta paradójico que se pongan los seres más amados al cuidado de las personas que más se subvaloran. El artículo se estructura en cinco apartes. El primero ubica metodológicamente la investigación identificando el proceso investigativo. El segundo muestra un análisis de contexto del momento en que se realizó la investigación y menciona experiencias organizativas que existían en torno a las reivindicaciones del trabajo doméstico remunerado a nivel nacional e internacional. El tercero plantea un marco analítico de la discriminación racial y de género a las trabajadoras domésticas. El cuarto recoge los principales resultados respecto de las condiciones laborales y de seguridad social de las mujeres trabajadoras domésticas afrocolombianas de Medellín y, por último, se exponen las principales reivindicaciones, logros y retos en el marco de las luchas de la Unión de Trabajadoras Afrocolombianas del Servicio Doméstico - (UTRASD).

Palabras clave: Afrodescendientes; Estudios de género; derecho del trabajo; trabajo doméstico; sociología del trabajo

\begin{abstract}
Paid domestic work is an activity that employs large numbers of Afro-Colombian women in the city of Medellin, due to historical issues of slavery, migration, lack of opportunities to study, discrimination in access to other jobs, among other situations. This has allowed other people, having someone to take care of their homes, to be able to carry out their life projects. However, it is paradoxical that the most loved ones are placed in the care of the people who are most undervalued. The article is structured in five moments. The first one methodologically locates the research by identifying what the research process consisted of. The second shows an analysis of the context of the time when the research was carried out and mentions organizational experiences that existed around the demands of paid domestic work at the national and international levels. The third presents an analytical framework of racial and gender discrimination against domestic workers. The fourth sets out the main results regarding the working conditions and social security of Afro-Colombian domestic workers in Medellin and, finally, presents the main demands, achievements and challenges that have been part of the struggles of the Union of Afro-Colombian Domestic Workers (Unión de Trabajadoras Afrocolombianas del Servicio Doméstico - UTRASD).
\end{abstract}

Keywords: Afro-descendants; Domestic Work; Gender Studies; Labour Law; Sociology of Work 


\section{Introducción}

Esta investigación, que inició en el mes de mayo de 2012 y su propósito fue recoger las experiencias de las mujeres afrocolombianas trabajadoras domésticas remuneradas de las diferentes comunas de la ciudad de Medellín, permitió identificar sus condiciones laborales y de discriminación racial en el lugar de trabajo ${ }^{1}$. Para ello, se contó con la experiencia de la Escuela Nacional Sindical (ENS) que, a partir de un compromiso constante con el avance de las condiciones de trabajo decente para los y las trabajadoras, ha adelantado varias investigaciones que develan la situación de la población colombiana, a partir de la preocupación que genera el distanciamiento que existe entre los planteamientos normativos, las políticas públicas y la realidad.

De igual forma, con este artículo se pretende dar cuenta de cómo fue la participación de las mujeres en la recolección de información y cómo esta participación llevó a un proceso de apropiación, emancipación y empoderamiento de las mujeres en la reivindicación de los derechos que la investigación develó, se vulneraban. Este empoderamiento llevó a que, como producto de la investigación, se creara la Unión de Trabajadoras Afrocolombianas del Servicio Doméstico -UTRASD-, organización desde la cual las mujeres han liderado procesos reivindicativos en la lucha de las mujeres trabajadoras domésticas remuneradas de Colombia. Son las mujeres afrocolombianas las que vienen liderando procesos organizativos orientados a luchar por hacer del trabajo doméstico remunerado un trabajo digno y con condiciones decentes; por ello, aquí se cuentan algunos de los logros que ellas han obtenido.

El propósito de divulgar esta experiencia es también poder contribuir al debate académico, teórico, metodológico y conceptual, relacionado con el trabajo decente de la población afrocolombiana y la discriminación racial. La discriminación racial de las mujeres trabajadoras del servicio doméstico es un tema que hoy ocupa las agendas de muchos actores y sectores de la sociedad y sobre el cual se viene avanzando, pero aún hace falta construir y fortalecer una agenda nacional que visibilice la problemática de discriminación racial que se traduce en precariedad laboral y que incide negativamente, y de forma directa, en las condiciones de vida de la población afrocolombiana. Por tales razones, el objetivo general de este artículo es describir las condiciones laborales y de discriminación racial de las mujeres afrocolombianas, que laboran en el servicio doméstico en la ciudad de Medellín.

\section{Proceso metodológico}

El diagnóstico fue concebido como un ejercicio en el que, desde la investigación cualitativa, se asumió como posible el entender la generación de conocimiento a partir de realidad social, de las percepciones, experi encias y vivencias de las personas en un contexto específico (Galeano, 2004). Ahora, dado que el diagnóstico se orientó a intentar dilucidar el contexto de las mujeres afrocolombianas que trabajan en servicios domésticos y la forma de percibir su realidad laboral, se optó por un enfoque hermenéutico. Bajo estos lineamientos fue posible que, simultáneamente con la recolección de información, se realizara la interpretación y discusión de los resultados obtenidos. En este sentido, se buscó que en la identificación de las condiciones laborales y de

\footnotetext{
${ }^{1}$ Es importante destacar que el diagnóstico fue concebido inicialmente para mujeres debido a que este trabajo ha sido tradicionalmente desempeñado por este grupo poblacional. Sin embargo, no se descartó la posibilidad de que los hombres que se identificaran en el oficio, pudieran ser vinculados al proceso.
} 
discriminación racial que sufren las mujeres que trabajan el servicio doméstico, se tuvieran en cuenta las percepciones, sentires y experiencias como forma de vincular metodologías que partan de las vivencias cotidianas y su forma de relacionamiento en el contexto específico de la ciudad.

También, se combinaron técnicas de recolección de información cuantitativas (encuestas) y cualitativas (observación, grupos focales, entrevistas, talleres), que permitieron no solo la obtención de datos, sino profundizar en aquellas situaciones que dan cuenta de cuáles son las condiciones laborales y de discriminación racial de las mujeres afrocolombianas que se dedican al trabajo doméstico remunerado. Aspecto que estuvo orientado a pensar en alternativas de acción desde la realidad y el panorama específico que viven las mujeres afrocolombianas sin partir de supuestos teóricos preestablecidos (Bonilla y Rodríguez, 2005).

El diagnóstico vinculó la participación activa no solo de mujeres afrocolombianas trabajadoras domésticas, sino que paralelamente incluyó diálogos con diferentes organizaciones que vienen desarrollando trabajos sobre asuntos de discriminación racial y derechos. Igualmente, en el marco de la elaboración del diagnóstico, se llevó a cabo la capacitación de mujeres para la creación y el fortalecimiento de una organización de trabajadoras del servicio doméstico, que buscara velar por la reivindicación de derechos laborales de las mujeres afrocolombianas. Este aspecto fue posible gracias a la experiencia y trayectoria del trabajo de campo de la Corporación Carabantú, que cuenta con amplia experiencia en acompañamiento de procesos organizativos en la ciudad, facilitado la vinculación de estas mujeres durante todo el proceso y el cumplimiento del objetivo general, antes mencionado, a través de los siguientes objetivos específicos:

- Identificar, según los lineamientos de trabajo decente establecidos por la Organización Internacional del Trabajo (OIT), los principales aspectos que dan cuenta de las condiciones de trabajo decente de las mujeres afrocolombianas que laboran como empleadas del servicio doméstico en Medellín.

- Evidenciar las principales prácticas de discriminación racial que sufren las mujeres afrocolombianas empleadas del servicio doméstico en Medellín.

- Fortalecer el proceso organizativo de un grupo de mujeres que trabajan en la reivindicación del trabajo decente de las mujeres afrocolombianas que se dedican al servicio doméstico en Medellín.

\section{Momentos del proceso metodológico}

Los momentos del proceso metodológico se presentan a continuación en una secuencia, pero no se desarrollaron de manera lineal. Cada uno de ellos estuvo sujeto a las particularidades de cada sector y a la disponibilidad de tiempo de las participantes; es decir, un momento no condicionó la realización del otro.

\section{Sensibilización}

Este momento metodológico consistió en el desplazamiento del grupo de investigación a realizar un proceso de formación (conversatorios, charlas, capacitaciones) dirigido a mujeres afrocolombianas empleadas del servicio doméstico, en el marco del diagnóstico de las 
condiciones de trabajo decente de este sector en la ciudad de Medellín. Uno de los territorios intervenidos fue el Parque de San Antonio, al ser un punto de encuentro representativo de un alto número de mujeres afrocolombianas que trabajan como empleadas del servicio doméstico. El total de mujeres que participaron de estos espacios fue de 120, logrando así incidir en las diferentes comunas de la ciudad en donde se cuenta con un número significativo de población afrocolombiana.

\section{Aplicación de encuestas}

Una vez realizado el proceso de sensibilización, se llevó a cabo la aplicación de las encuestas a las mujeres que expresaron su voluntad de continuar participando en el proceso y a otro grupo que fue referenciado por estas mismas mujeres y que, gracias a la estrategia de Voz a Voz o "Bola de Nieve", fue posible contactarlas y vincularlas a la investigación, logrando la participación de 42 mujeres de diferentes barrios de la ciudad. Dada la particularidad del estudio de corte cualitativo, no se empleó ningún muestreo estadístico para seleccionar las mujeres que participarían. La encuesta que se aplicó para recoger la información que aquí se analiza, contó con cinco módulos: 1. Caracterización, 2. Formas de contratación y de remuneración, 3. Seguridad social, 4. Diálogo social, y 5. Discriminación laboral y racial.

\section{Entrevistas}

Las entrevistas jugaron un papel importante durante la fase de recolección de información, en tanto que a través de estas se pudo no solo describir las condiciones laborales de las mujeres afrocolombianas que laboran como empleadas del servicio doméstico, sino que se pudo identificar las estructuras simbólicas y de significados que en las narraciones y conductas daban a su experiencia de trabajo (Tarrés, 2008). Estas fueron desarrolladas en dos sentidos, se entrevistaron mujeres que participaron en el proceso de sensibilización y en la encuesta y que llevaran más de diez años de experiencia como trabajadoras del servicio doméstico en la ciudad. También fueron entrevistadas algunas líderes que, no habiendo hecho parte de las mujeres encuestadas, debido a su experiencia como trabajadoras domésticas, podían dar testimonio sobre su experiencia laboral.

\section{Grupos focales}

Se realizaron cinco grupos focales en diferentes sectores de la ciudad, los cuales fueron seleccionados teniendo en cuenta aspectos como: lugares donde se identificó un número significativo de población afrodescendiente, según datos estadísticos de la ciudad; sectores referenciados en el diagnóstico de la población afrodescendiente que realizó la Alcaldía de Medellín durante el periodo 2010-2011; barrios en los que hay gran número de mujeres empleadas del servicio doméstico afrocolombianas y que se encuentren en estrato socioeconómico 1, 2 y 3 (Corporación Convivamos, 2011).

Los grupos focales constituyeron una técnica de recolección de información a través de la cual las mujeres afrocolombianas empleadas del servicio doméstico, expresaron libremente las percepciones acerca de sus condiciones laborales y de sus experiencias de vida en los lugares de trabajo. Para la constitución de los grupos focales se tuvo en cuenta a aquellas mujeres que participaron en la aplicación de la encuesta, y que de manera voluntaria decidieron hacer parte de estos espacios. Así mismo, se extendió la invitación a mujeres afrodescendientes que han 
tenido la experiencia de laborar como empleadas domésticas en la ciudad de Medellín, peroen la actualidad se encuentran desempleadas o desempeñando otras labores.

\section{Capacitaciones y resultado del proceso formativo ¡Del dicho al hecho!}

Las capacitaciones consistieron en la creación de espacios en los barrios en donde se contó con grupos de mujeres afrocolombianas que venía participando de los encuentros de sensibilización y expresaron interés por conocer alternativas para organizar un colectivo que garantizara el cumplimiento de sus derechos laborales. Con la orientación de un especialista en legislación laboral y en el tema afrocolombiano, se abordaron las herramientas que hoy se tienen para garantizar los derechos de quienes realizan este trabajo. Estos encuentros se llevaron a caboen cuatro sectores de la ciudad: Calasanz, Ocho de Marzo, Moravia el Oasis tropical y San Javier El Salado.

¡Del dicho al hecho! más que una frase, fue el lema que orientó todo el proceso formativo en legislación laboral, el cual estuvo orientado a identificar las condiciones laborales y de discriminación racial de las mujeres afrodescendientes empleadas del servicio doméstico de la ciudad de Medellín.

\section{Resultado del proceso formativo}

Durante las experiencias de diálogo y formación, se identificó que son varias las razones por las cuales las mujeres trabajadoras domésticas no acceden a los colectivos de mujeres, entre muchas, porque esta labor se percibe como transitoria y de supervivencia, ya que siempre se mantienen las expectativas de ascender y conseguir otro trabajo que permita mejorar su condición de vida. Por otro lado, las mujeres que desempeñan estas labores, particularmente no conciben el hogar como un espacio en el cual se labora y se presta un servicio, sino que lo perciben como su propio hogar; incluso, cuando dentro de su labor está el cuidado de niños y niñas, ellas afirmaron que los cuidan como a sus propios hijos.

Otra de las razones por las cuales estas mujeres no se vinculan a procesos organizativos para velar por derechos laborales, es el hecho de que ejercen sus labores de manera aislada y en soledad, en las cuatro paredes de la intimidad del hogar; situación que imposibilita, en la mayoría de casos, el contacto y la socialización con otras trabajadoras que desempeñan labores idénticas o afines. El desenvolvimiento e intercambio entre trabajadoras domésticas generalmente se da en espacios muy cortos y no necesariamente se usan para conversar sobre las condiciones en que se presta el servicio.

En esa medida, consideraban casi que imposible crear colectivos, máxime cuando las jornadas de trabajo son extensas y extenuantes, sumado a que los descansos en días feriados y fines de semana son reducidos. Otro factor que podría llamarse exógeno, que contribuye y agudiza la problemática planteada, es el hecho de que las trabajadoras domésticas no se han podido integrar a las agendas de movimientos sociales de mujeres, a los sindicatos, ni a actores sociales que reivindican derechos laborales, pese a que muchas de ellas (el 64,3\%) reconocieron que los sindicatos aportan a las luchas por los derechos laborales. En esta medida, no identifican acciones colectivas que recojan problemáticas laborales que, sin estar inmersas en el trabajo doméstico, puedan agrupar mujeres trabajadoras que quieran reivindicar sus derechos en el trabajo. Sin embargo, gracias al proceso formativo que se desarrolló con el grupo de las 68 
mujeres afrocolombianas empleadas del servicio doméstico, un 97,6\% consideraron que una asociación de mujeres trabajadoras del servicio doméstico en la ciudad de Medellín, mejoraría sus condiciones de trabajo, porque estando unidas pueden generar mayor impacto y ser escuchadas, aspecto que no han logrado de forma individual. Para lo anterior, optaron por la figura de sindicato al considerar que les permitiría vincular a las comunidades en las problemáticas que ellas sufren, y buscar una solución en conjunto; a través de este se podría tratar de regular los pagos de trabajos por días, se respetarían los horarios de trabajo, les pagarían lo justo, podrían continuar con sus estudios, vigilarían las formas de contratación y se vincularían a otras organizaciones que velan por el cumplimiento de los derechos laborales.

El proceso de fortalecimiento del grupo de mujeres fundadoras del sindicato, inició con la vinculación de estas a las diferentes discusiones que sobre los temas laborales, se generaban a nivel de ciudad. Uno de esos momentos fue la creación del Consejo Laboral Afrocolombiano, del cual algunas de las mujeres que participaron del diagnóstico hicieron parte activa ${ }^{2}$.

Una vez capacitado el grupo de mujeres, se consolidó el sindicato de mujeres trabajadoras en servicios domésticos, quienes se encontraban preparadas para liderar acciones orientadas a reivindicar este trabajo en la ciudad de Medellín. El sindicato denominado por las mujeres como Unión de Trabajadoras Afrocolombianas del Servicio Doméstico de siglas UTRASD, se registró ante el Ministerio del Trabajo el 1 de marzo de 2013 con 28 mujeres y a octubre del mismo año contaba con 160 mujeres afiliadas.

\section{Enfoques}

Los enfoques desde los que se abordó esta investigación responden en principio a un enfoque étnico-racial y de derechos dirigido a identificar la problemática laboral y de discriminación racial del trabajo doméstico, sacándolo del espacio íntimo para llevarlo a un nivel público, desde donde se plantean soluciones a una problemática que es de corte estructural. Porque para hablar sobre las condiciones laborales de las mujeres afrocolombianas, se requiere de una mirada multidimensional que permita observar la diversidad de procesos históricos, ideológicos, políticos, económicos, sociales y culturales que están imbricados en los diferentes escenarios. Se hace imposible comprender las condiciones laborales, mirando de soslayo, las consecuencias y manifestaciones de un fenómeno estructural como el racismo, este fenómeno o patología que aun la sociedad colombiana no acepta y tampoco lo interviene de manera directa. Igualmente, con frecuencia esta situación se identifica como un problema "íntimo" o subjetivo, dejando de lado su carácter económico donde tiene sus orígenes y desde donde se perpetúa y reafirma sus bases.

A lo largo del diagnóstico, también se tuvo en cuenta un enfoque participativo que permitiera establecer un escenario de diálogo social que posibilitara reivindicar los derechos de las mujeres que trabajan en empleo doméstico, reconociendo y desmitificando las estrategias de poder en relación con la raza, como lo han venido planteando ampliamente los estudios decoloniales como los de Wade (2008). Desde el mismo momento de cosificación de la persona negra como herramienta de trabajo, se instauró una concepción ideológica de conquista, dominación y

\footnotetext{
${ }^{2}$ El acto a través del cual se creó el Consejo Nacional Laboral Afrocolombiano, se llevó a cabo en la ciudad de Cali durante los días de junio del 2012. Participaron mujeres trabajadoras domésticas y Cortadores de caña.
} 
apropiación de las personas de raza blanca sobre las personas de raza negra, dejando claro para este momento que la calidad de raza era atributo solo de la persona blanca. Desde sus orígenes, el racismo tiene su base en la estructura económica, construyendo ideológicamente las justificaciones culturales y sociales para mantener la supremacía de una raza sobre la otra.

Las personas negras, mediante el giro ideológico del proyecto de Nación pluriétnica y multicultural, específicamente en la Ley 70 de 1993 donde se concreta el resultado de luchas históricas de líderes y lideresas por el reconocimiento como grupo étnico en el Estado Nación colombiano, plantearon la necesidad de desvincular la visión que se tenía sobre ellas del estado de cosificación y ser no pensante, fruto del proceso de esclavización. Momento histórico que no solo reconoce políticamente la deuda histórica de Nación, sino que además identifica la necesidad de adoptar mecanismos de participación que conlleven a que el pueblo afrocolombiano nutra con sus saberes la construcción del nuevo proyecto nacional pluriétnico y multicultural.

Por tanto, desde este enfoque se propone fortalecer los espacios de visibilización, diálogo y recuperación de memoria étnica de las mujeres empleadas del servicio doméstico, de tal manera que se puedan fortalecer y romper los círculos de exclusión social y económica, donde el empleo doméstico pueda ser una elección. De igual forma, un enfoque clave para abordar la problemática, es intervenirla desde el enfoque de género orientado a la mujer afrocolombiana como trabajadora en el servicio doméstico. Frente al proceso de re significación y recuperación de memoria étnica, si bien no se puede desconocer que las esferas de poder racista y poder sexista a menudo van de la mano, ambas constituyen formas de poder diferentes.

Frente a las actuales reivindicaciones del feminismo, es importante reconocer que para las mujeres afrocolombianas el tema contiene matices y procesos históricos diferentes. Esta relación de poder racial y sexista se mantiene viva y latente, pero invisibilizada, constituyendo la base desde la cual las mujeres afrocolombianas establecen relaciones a nivel laboral, social y afectivo. Por un lado, por el hecho de ser mujer afrocolombiana, se le atribuye el rol de trabajadora doméstica. Por otro, en relación con su cuerpo, el cual ha sido erotizado o mirado como objeto de placer. Por último, como resultado de su proceso histórico y de resistencia, su cuerpo no carga, en el sentido del feminismo clásico, una idea de fragilidad sino de fuerza y resistencia física.

\section{Contexto en el que se ubica la investigación}

Como se mencionó, durante el año 2012 la Escuela Nacional Sindical (ENS) y la Corporación Afrocolombiana de Desarrollo Social y Cultural (Carabantú), se unieron para profundizar sobre el escenario laboral de las trabajadoras afrocolombianas del servicio doméstico en la ciudad de Medellín, como forma de respuesta al Plan de Acción del Gobierno Nacional interesado en generar un serie de normas que buscaban el mejoramiento de las condiciones laborales de este sector, entre las que se incluyen la Ley 1595 del 2012, mediante la cual se ratifica el Convenio 189 de OIT, sobre el trabajo decente para los y las trabajadoras domésticas, situación que abre un panorama internacional para la vigilancia en este grupo poblacional.

Adicionalmente, en el país existían ya sustentos legales que amparaban los procesos de recuperación de memoria histórica y reivindicación étnica. En Colombia, la Constitución 
Política de 1991, en sus artículos 7, 13, 63, 68, 70, 176 y 310, hace un reconocimiento a los derechos de la población afrocolombiana, negra, palenquera y raizal; así como la Ley 70 de 1993, la cual propone adjudicar a las comunidades negras las tierras baldías que han ocupado en las riberas de los ríos de la cuenca del Pacífico y establecer mecanismos para la protección de su identidad cultural, sus derechos como grupo étnico y el fomento de su desarrollo económico y social.

Sin embargo, pese a los mecanismos legales establecidos, que se reúnen en los esfuerzos de diferentes movimientos afrocolombianos y de organizaciones que vienen trabajando el tema afro, las mujeres trabajadoras del servicio doméstico en la ciudad de Medellín no contaban con un trabajo decente y productivo en condiciones de libertad, igualdad, seguridad y dignidad humana. Aspecto que constituye una señal de alerta para hacer seguimiento a las acciones que se enmarcaron desde la constitución política y los diferentes organismos internacionales que regulan el trabajo. Para el caso del trabajo doméstico, es una lucha, en primera instancia, contra las prácticas de discriminación racial: "una base fuerte es la lucha contra el racismo, visto tanto como la negación del acceso igualitario a las clases sociales; así como la negación o la interiorización de la diferencia del ser negro" (Wade, 2008, p. 135).

Si bien no se trata de cambiar la estructura del sistema social capitalista; se trata de develar y desmontar los mecanismos, ideologías y concepciones que impiden al interior de un sistema social democrático, establecer procesos de intercambio y diálogo hacia la equidad social, política y económica. Por tanto, el empleo doméstico, hacia la esfera de trabajo decente, es la base desde donde se propicia un escenario de inclusión y equidad social a las mujeres empleadas domésticas, donde pueden orientarse hacia la utilización de sus habilidades en pro del desarrollo de una economía propia; es decir, siendo este el medio y no el fin para la búsqueda de alternativas económicas con dignidad, así como lo estipuló la Comisión Interamericana de Derechos Humanos (Comisión IDH, 2011), la cual:

Considera imprescindible que los Estados de la región adopten medidas positivas para erradicar la discriminación racial en el hemisferio y garantizar efectivamente los derechos de las personas afrodescendientes. Para ello es imprescindible contar con la información, adecuada y desagregada y destinar los recursos humanos y financieros suficientes y específicos que permitan no sólo desactivar los prejuicios y estereotipos raciales sino también mejorar las condiciones de vida de las personas afrodescendientes en lo que se refiere a salud, vivienda y trabajo, haciendo especial hincapié en la situación de triple discriminación que padecen las mujeres afrodescendientes (p. 77).

Así mismo, establece el principio de la no discriminación como uno de los pilares de cualquier sistema democrático (Comisión IDH, 2011). Esta investigación parte también de la noción de trabajo decente propuesta por la Organización Internacional del Trabajo (OIT), que viene 
avanzando en la construcción de indicadores para medir la calidad y las características del trabajo decente de las personas que prestan servicios domésticos. En este sentido, esta investigación responde a un contexto en el que primero se ve una apertura legal tanto nacional como internacional que garantiza y reconoce derechos para los y las trabajadoras domésticas y para la población afrocolombiana, pero también responde a una necesidad de que se gesten colectivos en la reivindicación y exigencia de cumplimiento a este nuevo marco legal, ante la ausencia de otros colectivos o sindicatos que abanderaran el tema y lo hicieran desde un enfoque étnico-racial.

Si bien a la fecha de la investigación ya se habían creado en Colombia organizaciones comoel Sindicato de Trabajadoras del Servicio Doméstico SINTRASEDOM (creado en la ciudad de Bogotá desde la década de 1980) y la Confederación Latinoamericana y del Caribe de Trabajadoras del Hogar - CONLACTRAHO (creada en 1988 en el ámbito regional), existía un debilitamiento generalizado de estas organizaciones que habían sido tan fuertes en décadas pasadas. Por esta razón, no existía un posicionamiento fuerte del tema en Colombia, en principio por la falta de datos que develaran la situación real de las mujeres trabajadoras domésticas, como de colectivos o sindicatos de mujeres que posicionaran el tema en la agenda pública. Es en respuesta a esta ausencia, y como producto de esta investigación, que nace la Unión de Trabajadoras Afrocolombianas del Servicio Doméstico - UTRASD como una organización sindical que, a partir del diagnóstico, formación y reivindicación de derechos, empieza sus procesos de incidencia para la transformación y el goce efectivo de derechos en el sector de las trabajadoras domésticas.

\section{Discriminación laboral racial hacia las mujeres trabajadoras domésticas afrocolombianas de Medellín}

Estudiar las condiciones laborales de las mujeres afrocolombianas empleadas en el servicio doméstico en un contexto específico como la ciudad de Medellín sirvió como pretexto para visualizar el lugar del racismo en el escenario laboral, y con ello la posición actual de la mujer afrocolombiana en la sociedad intercultural. No fue imposible diagnosticar las condiciones laborales de las mujeres empleadas en el servicio doméstico, sin observar como categoría central, una enfermedad fáctica como el racismo estructural (Lao-Montes, 2007). Encontramos entonces en el diagnóstico, la necesidad de develar todas las manifestaciones que contribuyen a desmontar el mito generalizado de la inexistencia del racismo en la ciudad de Medellín. El racismo identificado está sustentado en una concepción de poder existente en un grupo poblacional mestizo "paisa", trasmisor de una ideología colonizadora que ostenta una posición superior sobre la población afrocolombiana que reside en la ciudad, bien sea por migración, desplazamiento o nacimiento.

Según algunos académicos, en un proyecto de nación intercultural es mejor no hablar de barreras raciales, sino de un proyecto multiétnico e intercultural. Sin embargo, ésta división entre mestizo-afrocolombiano aún se mantiene presente en la práctica, como se demostró en el estudio realizado por Wade (1987) denominado "los chocoanos en Medellín", en donde muestra que al referir los lugares en donde geográficamente se identifica mayor población afrocolombiana, se nombra como "el departamento negro de Colombia", aspecto que se mantiene presente en expresiones como la que recientemente pronunció un Diputado de la 
Asamblea Departamental de Antioquia en la ciudad de Medellín, al referirse a la inversión en el Departamento de Chocó con la expresión: “invertir en el Chocó es como echarle perfume a un bollo", como si ello no implicara una inversión en el país.

Además, resulta difícil para los medellinenses en general, reconocer que una persona afrocolombiana es nacida u originaria de la ciudad de Medellín. Igualmente se identifica que entre las personas afrocolombianas es peyorativo y hasta jocoso, identificarse o nombrarse como "afropaisa", puesto que el gentilicio "paisa" para muchas personas afrocolombianas tiene una connotación de la persona que explota, maneja y se apodera de los recursos. Estas concepciones no son gratuitas e injustificadas, por el contrario, llevan consigo una carga histórica y cultural naturalizada.

En Medellín, por ejemplo, se encontró, a partir de esta investigación, que otra barrera racial en el lenguaje es la expresión de uso cotidiano "Yo no soy negra de nadie". Para efectos de comprensión de esta expresión, se realizaron algunas entrevistas y varios conversatorios con personas que admitieron conocer o haber utilizado la expresión (en dicho ejercicio participaron profesionales, empleados, empleadas y estudiantes; ninguno perteneciente al grupo étnico afrocolombiano). Al preguntar a estas personas a lo que hacía referencia dicha frase, se encontró que, en su gran mayoría, la empleaban para hacer referencia a una sobrecarga laboral, es sus palabras: "cuando le dejan a uno todo el trabajo", "cuando le ponen a hacer todo el trabajo a uno hasta el de los otros". Manifestaron además, que en otras ocasiones la misma frase la relacionaron a la expresión "trabajé como negra", aludiendo a las condiciones y a la fuerza de trabajo, que según lo expresó una participante: "yo nunca me he centrado o (referido) al no reconocimiento del trabajo, sino como en el maltrato".

En su gran mayoría, nombraron que utilizaron o escucharon la expresión "Yo no soy negra de nadie", para remplazar la frase "no soy empleada doméstica o criada de nadie". En síntesis, estas frases son usadas para referirse a una sobre carga laboral, cuando no es dignamente remunerada o valorada o cuando la tarea a realizar no la encontraron afable. En ninguno de los casos se encontró referencia a la fortaleza física, habilidad o a las destrezas, orales y gastronómicas, que con frecuencia reconocen los empleadores a la hora de preferir a las mujeres afrocolombianas en el oficio de empleadas domésticas.

Dicha expresión no solo demuestra la concepción general del rol laboral que la ciudad le ha asignado a la mujer afrocolombiana como empleada en el servicio doméstico, sino que además demuestra el conocimiento de las condiciones de este trabajo y la concepción peyorativa que se tiene del mismo. El ejemplo manifiesta algunos aspectos sobre la profundidad de las brechas históricas raciales existentes entre la población afrocolombiana y mestiza que reside en la ciudad de Medellín. Escenario desde el cual no se puede desconocer la realidad de la población afrocolombiana en la ciudad, que representa el centro simbólico de la raza mestiza antioqueña, portadora simbólicamente de cierta "pureza" racial, de una concepción colonizadora que guarda para sí la calidad de personas intrépidas, comerciantes, negociantes, una concepción fácil de mantener, mientras que el capital social permanece concentrado en este grupo poblacional, que tiene gran incidencia en la calidad de vida de los y las afrocolombianos en la ciudad.

En la misma línea de racismo estructural, Medellín como lo han venido evidenciando diferentes estudios, y que se ratifica en este diagnóstico, se convierte en receptora de la población ya que 
la mayoría de las participantes provienen de diferentes zonas del Pacífico colombiano, migrantes de sus territorios "empobrecidos" en busca de mejores condiciones de vida, lo que las pone en situación de destierro y en una lucha por retornar, por recuperar su autonomía y mantener viva su relación histórica con los territorios desde los lugares que habitan (Arboleda, 2007).

Se ha identificado que la dominación y exclusión histórica que sufren los pueblos afrocolombianos, corresponden a una larga historia de destierro forzado, de violencias físicas, culturales y sistémicas, que tienen su origen en el siglo XV como consecuencia de la trata transatlántica, desde cuando se naturalizó la exclusión social, la discriminación socio racial, la exclusión política y desvalorización cultural de los pueblos afrodescendientes (Lao-Montes, 2007). Igualmente, los racismos latinoamericanos son sistemas de dominio étnico- racial cuyas raíces históricas se enclavan en el colonialismo europeo, así como su legitimación en la conquista, la explotación, el genocidio y en la esclavitud (Posso, 2008).

No encontramos para Medellín, un estudio diferenciado de las particularidades en aspectos de migraciones afrodescendientes. De hecho, para la fecha de realización de la investigación, se generaliza el desplazamiento forzado a aquellas mujeres que logran demostrarlo mediante su inscripción en el registro único de población desplazada (RUPD), de las que también participó un número significativo en la ejecución de este proceso de diagnóstico.

De todas formas, una vez inmersas en la ciudad, esta les brinda a las mujeres afrocolombianas una casi única opción de desarrollo económico: el empleo en el servicio doméstico, alternativa económica con pocas o nulas condiciones de trabajo decente. Aunque muchas de ellas inicialmente lo adoptan como una situación pasajera, al pasar el tiempo se apropia como una forma de vida permanente y en punto de referencia de subsistencia para sus amigas y familiares, residentes y entrantes a la ciudad, pero que no responde al deseo de estas mujeres: "yo hago este trabajo porque me toca"; "a mí no me gusta decir que trabajo en casas porque muchas veces no lo respetan a uno, y porque ya lo miran a uno como de menos". Estas fueron respuestas reiterativas de muchas de las mujeres ante la pregunta de por qué su elección laboral. Situación ante la cual muchas de ellas adoptan como una de las alternativas de escape, el encuentro en sitios específicos de la ciudad, que les permite tramitar y resistir sus realidades económicas y sociales con otras personas en sus mismas condiciones. El parque San Antonio, en Medellín, es un punto en donde se realizaron valiosos encuentros con las mujeres empleadas del servicio doméstico durante el desarrollo de este diagnóstico.

En estos espacios se observó que allí se mantienen y conservan encuentros interétnicos que representan la conservación de las relaciones entre las mujeres y sus paisanos. También desde donde cada una de ellas pueden tramitar por medio de "asesorías" y diálogos, su situación laboral y asuntos de envío de recursos a sus seres queridos. "Quien quiera hallarse con una paisana viene al Parque de San Antonio". Estos encuentros también permitieron reconocer, entre otros aspectos significativos, la necesidad del diálogo hasta entonces aplazado que tienen las mujeres afrocolombianas con otra forma de poder que se relaciona específicamente con su condición de mujer y sus realidades en particular.

Esta interlocución de las mujeres afrocolombianas que trabajan como empleadas del servicio doméstico en la ciudad de Medellín y que se muestran en el diagnóstico, revelan unas 
condiciones generalizadas de vulneración de los derechos laborales, siendo este un oficio que se ejecuta por fuera de los lineamientos de la legislación laboral. Son las familias contratantes, las que establecen las condiciones de trabajo de manera subjetiva y arbitraria, representándole a las mujeres que ejercen esta labor la completa negación a su ser, que comprende una discriminación racial de las mujeres como raza humana que pertenece a un grupo étnico diferente, con un proceso histórico étnico que les pertenece, una historia, una cosmovisión, unas particularidades fenotípicas diferentes y unas formas de relacionarse con el mundo desde su singularidad étnica. Aspecto que se observó en las frecuentes prácticas de discriminación racial que soportan las mujeres tanto en sus lugares de trabajo como en algunos espacios de la ciudad, y cuando solo las conciben en el rol de empleadas domésticas por el hecho de ser mujeres afro, que las conduce a un proceso de resignación o blanqueamiento.

La desprotección de la seguridad social, las horas excesivas de trabajo aun no reguladas ni reconocidas como horas extras, son condiciones del trabajo doméstico incompatibles con los tiempos familiares de las personas que lo ejercen y limita o niega muchas veces el acceso a los espacios de diálogo social, cuyo sentido adquiere una dimensión vital, estrechamente relacionada con la participación política y el desarrollo democrático, así como la vinculación a procesos de sanación, recuperación y revitalización de memoria ancestral para la mujer afrocolombiana.

Las mujeres afrocolombianas empleadas del servicio doméstico están subordinadas al poder económico que les perpetúa un contexto de marginalidad, generando todas las condiciones para repetir el círculo de subdesarrollo económico, aún más menguando sus posibilidades de incluir su capital social, saberes hacia la implementación del desarrollo económico nacional. Más allá de nombrarlas como "mujeres pobres" o "vulnerables", es reconocerlas como mujeres obligadas a permanecer en un mismo círculo económico en el cual en últimas, lo que se encuentra en juego es su posibilidad de elección.

Se encontró que muchos líderes y lideresas, ante la falta del fortalecimiento económico organizacional, se ven obligados a dividir constantemente su tiempo en tramitar, hacer exigibles sus derechos, fortalecer los procesos de autoreconocimiento y revitalización del saber propio para el desarrollo económico, social y cultural. Muchas propuestas de desarrollo económico desde sus saberes propios, como la danza, la gastronomía, la etnoeducación, entre otros, generalmente son relegadas al espectáculo, al contrato esporádico o a un espacio exótico, puesto que muchos procesos se encuentran subordinados a la voluntad del político de turno y muchas veces no se cuenta con recursos para poner en marcha iniciativas económicas.

\section{Discriminación laboral racial: una revisión impostergable}

En esta misma medida la discriminación racial específica en el mercado laboral, viene siendo un asunto de preocupación en los últimos años, debido no solo a las condiciones de pobreza, desigualdad social y exclusión de la población afrodescendiente a nivel mundial, sino a la relación de dicha desigualdad con las precarias condiciones laborales que este grupo poblacional presenta. El informe de la Comisión Interamericana de Derechos Humanos (Comisión IDH) muestra cómo en las Américas las estadísticas ubican a la población afrodescendiente en los puestos más bajos en la escala laboral y que mayoritariamente realizan tareas informales y de baja calificación. Sumado a esto, la población afrodescendiente cuenta 
con una remuneración menor, incluso si se comparan sus salarios con los de personas no afrodescendientes que realizan las mismas tareas. Así mismo, se muestra que la tasa de desempleo de este colectivo es mayor que la del conjunto total de la población (Comisión IDH, 2011, p.24).

Numerosos estudios dan cuenta del fenómeno de la discriminación racial a nivel nacional: Pardo, Mosquera y Ramírez (2004) presentan una panorámica sobre las principales investigaciones que se vienen realizando para visibilizar esta problemática en el Pacífico colombiano. En esa misma medida, sobresale el trabajo de Portilla (2003), Arocha (1998) y (2004), Barbary y Urrea (2004) y Romero (2007), quienes vienen evidenciando en sus investigaciones cómo la discriminación racial en el país se ha venido agudizando en los últimos años.

En esta misma línea y para el caso específico de Colombia, un reciente estudio en el que participaron la Escuela Nacional Sindical, la Universidad de Antioquia, la Universidad de Cartagena y la Universidad del Valle, muestra que un alto porcentaje de trabajadores asalariados e informales manifestó haber sido víctima de discriminación racial laboral por su condición de afrocolombiano o afrocolombiana. Encontrándose que, en comparación con las ciudades de Cali, Buenaventura y Cartagena, el porcentaje más alto de discriminación laboral racial se registra en la ciudad de Medellín con un 43,8\% (Correa, Pérez, Viveros y Morales, 2011, p. 262).

En cuanto a las mujeres afrocolombianas que trabajan como empleadas del servicio doméstico en la ciudad de Medellín, la realidad no es diferente a lo que se registra en los informes nacionales e internacionales. Sumado a otras discriminaciones entre las que sobresale la discriminación por asuntos de género, se suma la discriminación racial de la cual son víctimas en sus lugares de trabajo. Los datos que arrojó el diagnóstico sobre las condiciones laborales de las mujeres afrocolombianas trabajadoras del servicio doméstico en la ciudad de Medellín, dan cuenta de una realidad que silenciosamente se ha venido agudizando en los últimos años, como es el caso de la discriminación racial que sufre la población afrocolombiana en algunos espacios laborales. Para este diagnóstico, la discriminación se asumió como un término que aplica a grupos claramente identificables por sus características físicas, étnicas, sus prácticas sociales o por cualquier otro rasgo fácilmente observable. Si bien otros estudios plantean que la discriminación que sufren las mujeres afrocolombianas se presenta por diversos factores como: discriminación por género ${ }^{3}$, condición socioeconómica, discapacidad y edad, entre otros. El tema de discriminación racial en el ámbito laboral resulta preocupante al poner a este grupo poblacional en una situación de triple discriminación.

Este asunto ha sido cuestionado por los colectivos de organizaciones que abordan el tema desde hace más de tres décadas y ha llevado a que en los últimos censos de población, encuestas a hogares y estadísticas vitales, entre otros estudios, se incluya el enfoque étnico-afro en la mayoría de los países de América Latina. Sin embargo, se requiere de alternativas desde las diferentes organizaciones e instituciones para aportar a la mitigación de la problemática que sufren las mujeres afrocolombianas. Hoy los estudios continúan evidenciando que la población

${ }^{3}$ Como es el caso de los estudios de Tenjo (1992) y Perfetti (1996) en donde se evidencian diferencias salariales de las mujeres con respecto a los hombres. 
afrodescendiente muestra mayor vulnerabilidad sociodemográfica y peores condiciones de vida, en general, frente a la población no afrodescendiente. Situación que para las mujeres que trabajan como empleadas del servicio doméstico se torna más compleja, cuando se suma la discriminación por género o etnia que ubica a las mujeres en los empleos peor remunerados.

\section{Discriminación racial en los lugares de trabajo en la ciudad de Medellín}

El escenario para las mujeres afrocolombianas que trabajan en el servicio doméstico en la ciudad de Medellín muestra que el 55\% de las mujeres que desempeñan este oficio han sido víctimas alguna vez de discriminación en su lugar de trabajo. El hecho de ser mujeres de piel negra, afirmaron las participantes, se convierte en el principal factor de discriminación racial que se manifiesta en muchas ocasiones por medio de burlas y chistes, específicamente por parte de los niños, niñas y jóvenes que habitan en los hogares en los cuales trabajan. Las mujeres manifestaron que con frecuencia remedan su forma de hablar, cuestionan prácticas culturales y prohíben cocinar los alimentos propios de su región. Al respecto una mujer expresó:

A mí me da pena comer mis comidas en mi trabajo como: mi plátano, mi pescado, mis bananos cocinados o el queso frito; porque dicen que esas comidas huelen maluco, que la casa queda todo el día con mal olor (...) aunque a uno no le guste mucho algunas comidas uno se acostumbra, le toca porque está en casa ajena.

Existe racismo, acá donde estamos acá sí hay racismo, con palabras a uno lo tratan mal, hay varios que son más racistas, incluso hacen chiste de uno como negros, delante de uno y se echan a reír, más lo hacen cuando están varios paisas reunidos.

Otro de los aspectos por los cuales algunas mujeres manifestaron que sí existe discriminación en su lugar de trabajo, específicamente racial, está relacionada con algunas prácticas que llevan a cabo en los hogares en los cuales trabajan como por ejemplo: la separación de platos, cuchillos, vasos, cucharas y demás utensilios de cocina de uso exclusivo para las empleadas domésticas afrocolombianas. Las mujeres que han tenido la experiencia de trabajar en hogares donde hay dos empleadas, generalmente una para la cocina y otra para el aseo general de la casa, la separación de utensilios de cocina no aplica necesariamente para la empleada mestizas, sino para las afrocolombianas.

Otra práctica que identifican como discriminatoria es el no poder sentarse a consumir los alimentos (desayuno, almuerzo o cena), específicamente cuando los empleadores o patrones están en los hogares o cuando se cuenta con invitados. Manifestaron además que consideran esta una práctica de discriminación racial, porque cuando hablan del tema con otras mujeres mestizas que laboran en el servicio doméstico, estas manifiestan que a ellas sí les permiten sentarse a comer, aunque aclaran que igualmente ocurre con las mujeres afrocolombianas, a ellas también les asignan unos sitios específicos para hacerlo, en la cocina, el patio de la casa o en su habitación.

A uno no le dicen que no tiene prohibido sentarse a almorzar, pero cuando uno lo hace siempre ellos piden algo a la mesa o debe cuidar los niños mientras ellos comen y cuando uno dice que está ocupado, se enoja y lo regañan o lo 
miran a uno fijo y se quedan la señora seria todo el día. Uno tiene que estar dispuesto a toda hora, yo mejor almuerzo mientras lavo los platos.

Por otro lado, una de las prácticas que con mayor frecuencia identificaron como discriminatoria las mujeres afrocolombianas que trabajan en el servicio doméstico, es el hecho de tener que esperar a que todos los miembros del grupo familiar en donde trabajan, consuman los alimentos preparados para ellas saber si deben hacer algo para ellas o si sobró de lo preparado para almorzar:

En donde yo he trabajado esto ocurre especialmente cuando piden la comida a domicilio. Por ejemplo, piden un pollo y uno lo pone en la mesa y cuando todos terminan uno mira si quedó para uno almorzar, sino uno se hace algo diferente para uno y completa.

Otra práctica que nombran como discriminatoria es el hecho de escuchar permanentemente a los miembros de la familia en donde trabajan, que establecen temas de conversación alusivos a su aceptación de las personas negras. Es frecuente escuchar comentarios como: aquí no somos racistas, las personas negras nos gustan mucho para trabajar porque son más aseadas, serias, decentes y educadas; yo tengo una muy buena amiga que es negrita, entre otros comentarios que inician fuera de contexto o como forma de recordarles que ellas son distintas.

Frente a la pregunta ¿Alguna vez usted ha sido víctima de discriminación en su trabajo?, muchas mujeres respondieron afirmativamente; sin embargo, un $43 \%$ dijo no haber sido víctima de discriminación racial durante la encuesta, pero se identificó durante las entrevistas y las capacitaciones que estas mujeres no consideran ninguna de las prácticas anteriores como discriminatorias, así como tampoco consideran que los chistes sobre personas negras sean un problema porque ellas son indiferentes ante cometarios que se hagan.

La situación de indiferencia de muchas mujeres del servicio doméstico ante prácticas discriminatorias es un asunto preocupante debido a que se viene familiarizando con chistes y cometarios que no identifican como racistas por temor a ser rechazadas o cuestionadas. Muchas de las mujeres, a pesar de escuchar en sus lugares de trabajo frases como: "Estoy trabajando como negra", "Esa labor es de negras", "Huele a negra", "Yo no soy la negra de la familia", entre otras, se están familiarizando con ellas y no logran identificarlas como racistas, sino como parte del lenguaje cotidiano.

Sumada a la discriminación sentida por las mujeres afrocolombianas en sus lugares de trabajo, también un $31 \%$ manifestaron haber soportado algún tipo de discriminación racial para conseguir empleo en algún oficio en particular, incluso en los lugares en donde trabajan, a pesar de identificarles más habilidades para trabajar, las conciben siempre como empleadas domésticas:

Recuerdo que yo estaba muy feliz porque por fin había terminado mi bachillerato. Entonces le dije a la patrona de mi mamá (en donde yo trabajaba durante las vacaciones del colegio cuidándole las hijas o haciendo remplazo de la señora de la cocina), que me ayudara a conseguir trabajo que había terminado. Ella me contestó que cuando alguna de sus hermanas necesitara una empleada me decía, me sentí triste porque ella pensaba que solo podía trabajar en casas. 
Cuando vine a Medellín a buscar trabajo, busqué en almacenes y nada que me daban trabajo, en cacharrerías y tampoco, hasta fui por allá a un hospital porque necesitaba para hacer aseo y camine y camine y lo único que me resultó fue en una casa.

Las mujeres manifiestan que, al momento de buscar empleo, es más frecuente que las rechacen por ser negras en otros lugares o para otros oficios, mientras en las casas de familia muchas veces las prefieren por ser más fuertes para trabajar, aseadas y por tener experiencia con niños; además las prefieren por saber preparar alimentos específicos como arroz con coco, pescados, mariscos y comida de mar en general.

Yo sé que no debo buscar trabajo como recepcionista, secretarias o asistentes y esas cosas así, porque esta gente en Medellín prefiere mujeres paisas, monas y de ojos verdes para esos oficios, yo no pierdo mi tiempo.

Siempre he trabajado en casas y nadie hasta ahora me ha dicho que no me reciben por ser negra, yo tengo muy buenas referencias y siempre he trabajado recomendada por paisanas y ellas saben de mi trabajo y de la calidad de mi trabajo.

En síntesis, en los diálogos con algunas mujeres, se encontró que la indiferencia frente a las prácticas de racismo se viene naturalizando como estrategia de subsistencia. Esto se evidenció cuando ellas decían: "Yo no le paro bolas a esas cosas que dicen pa'no meterme en problemas, yo lo que necesito es trabajar".

Frente a la situación de discriminación racial que sufren las mujeres empleadas del servicio doméstico en la ciudad de Medellín, estas no identifican políticas o normas mínimas para la no discriminación en los lugares de trabajo. Al momento de preguntar ¿Existe en su lugar de trabajo alguna política o norma orientada a favor de la equidad de género, color de piel, étnica, condición socioeconómica, edad o por cualquier otra razón?, el $88 \%$ respondió que no y solo el $2 \%$ respondió que sí existe. Igualmente, manifestaron las mujeres afrocolombianas empleadas del servicio doméstico, que estas experiencias de discriminación que sienten en los lugares de trabajo, en muchas ocasiones no se denuncian o no se mencionan por varios factores entre los que sobre salen:

- Temor a no ser recomendados por sus amigos, vecinos o familiares en otros trabajo por el hecho de ser consierado como problemático o problemática.

- Temor a ser señalados como acomplejados por sus amigos o vecinos, que no consideran que la situación corresponda a una práctica discriminatoria, sino que no se hizo bien el trabajo asignado.

- Temor al no tener cómo demostrar que fueron víctimas de discriminación racial. Los compañeros de trabajo generalmente son indiferentes ante prácticas de racismo por temor a meterse en problemas con sus jefes o superiores.

\section{Condiciones laborales y seguridad social de las trabajadoras domésticas afrocolombianas de Medellín}

Es necesario precisar que tradicionalmente se han identificado tres modalidades para desempeñar el servicio doméstico en la ciudad de Medellín: 
Empleada interna. Esta se presenta cuando la persona que ejerce este trabajo reside en el sitio de donde desempeña sus funciones; es decir, que las mujeres duermen en la casa en las cuales trabajan y solo salen para sus casas a descansar los días sábados a partir de las dos o tres de la tarde. Ellas generalmente deben reanudar sus labores el día domingo en las horas de la noche o el lunes en horas de la mañana.

Empleada externa o que no residen en el sitio de trabajo; es decir, que las mujeres laboran durante toda la semana en un mismo hogar, pero no duermen allí. Una de las particularidades para nombrar esta modalidad es el hecho de contar con al menos cuatro días de trabajo a la semana con el mismo empleador.

Empleada por días, es decir, que las mujeres no residen en el lugar de trabajo y laboran solo unos días de la semana para varios empleadores. Una de las particularidades que tiene esta modalidad de trabajo es el hecho de que en los hogares en donde las mujeres son contratadas, agrupan la mayoría de las labores del hogar para que sean desarrolladas durante el día que se tiene contratada a la mujer, resultando esto en sobrecargas laborales.

\section{Características y modalidades en las que se presta el servicio}

Las mujeres afrocolombianas que trabajan en labores domésticas en su mayoría han trabajado siempre en este oficio un $71 \%$; las demás, el $28 \%$ restante, han desempeñado otras labores. Sin embargo, las mujeres que dicen no haber laborado siempre en el servicio doméstico, han trabajado haciendo labores similares como por ejemplo aseo en restaurantes, oficinas, apartamentos y viviendas nuevas antes de ser asignadas y cocinando en restaurantes o en ventas ambulantes.

Yo antes tenía mis ventas de comida y me iba bien, pero como me toco venirme, me tocó dejar todo y ahora volver a conseguir la plata para trabajar de mí cuenta es muy complicado y lo que gano con los días que tengo apenas me alcanza para los gastos de la casa.

Con relación a la periodicidad con la que se ha prestado el servicio, el $78 \%$ lo ha hecho de forma permanente, mientras un $11 \%$ ocasionalmente y un $9 \%$ lo hace estacionalmente, como por ejemplo en vacaciones. Vemos como un alto porcentaje de estas mujeres se dedican a las labores del servicio doméstico permanentemente y muchas de estas manifiestan que siempre han laborado como trabajadoras domésticas, situación que nos demuestra un estancamiento laboral de este sector en tanto las mujeres que empiezan, permanecen en el tiempo como trabajadoras domésticas sin posibilidad alguna de ascenso laboral, configurándose de esta forma una movilidad horizontal que va desde trabajar como trabajadora interna en sus inicios, moverse a trabajadora externa y finalmente alcanzar a trabajar por días para de esta forma tener lo que llaman las mujeres más independencia.

La modalidad de contratación para el servicio doméstico que más sobresale en la ciudad de Medellín es el trabajo por días; el 52\% labora bajo esta modalidad; seguido de quienes trabajan interna en un $26 \%$. El $21 \%$ de las mujeres trabajan en la modalidad de externas. Esta última modalidad de contratación, según las participantes, resulta más agotadora debido a los desplazamientos a los lugares de trabajo y por las labores que deben realizar, pero les permite 
estar al cuidado de sus hijos pues, como se mencionó antes, solo una de las participantes no tenía hijos.

Así pues, como se indica en la Figura 1, en la actualidad la mayoría de las trabajadoras domésticas desarrollan su labor por días, fenómeno abiertamente contrario a lo que pasaba en Colombia en los años 1988 y 1989, en donde el 60\% de las mujeres trabajaban como internas, el $32 \%$ eran externas y por días o con varios empleadores solo trabajaba el $8 \%$ de las mujeres (Huyette, 1994 citado en Lautier, 2003).

Figura 1. Modalidad de la prestación del servicio

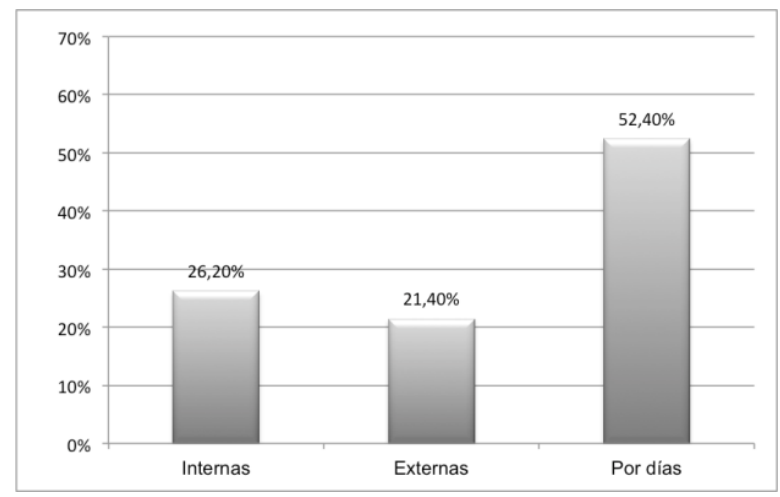

Fuente: elaboración propia.

Pese a que a algunas mujeres les resulta ventajoso trabajar por días para atender a sus grupos familiares, otras mujeres expresaron inconformidad con esta forma de contratación al considerar que las jornadas son muy largas porque se tiene establecida hora de entrada, pero no hora de salida. Argumentan además que no alcanza el día porque se tiene todas las labores para una sola jornada laboral, lo que hace que lleguen a sus casas sin ganas de realizar actividades de limpieza o preparación de alimentos, y mucho menos con ganas de acompañar a sus hijos en la realización de actividades escolares.

Igualmente, estas mujeres expresaron durante las entrevistas que no pueden pedir permisos en sus lugares de trabajo para asistir a reuniones escolares porque, aunque saben que es un derecho, les asignan en sus lugares de trabajo la responsabilidad de "despachar" o atender a los hijos de sus empleadores para que asistan al colegio. Igualmente deben preparar los alimentos para cuando algún miembro de la familia regrese del trabajo o del estudio, pues el $45 \%$ trabaja para familias con entre cuatro a cinco integrantes, el $38 \%$ con familias entre uno a tres integrantes y $11 \%$ trabaja en hogares con entre seis a diez integrantes. El trabajo por días es más frecuente cuando las familias contratantes son muy extensas. Ahora, la modalidad de trabajo por días para realizar solo una función, si bien no se presentó en las mujeres encuestadas, algunas de las participantes entrevistadas manifestaron haber sido en algunas épocas contratadas para sólo una labor. Las labores individuales que más contratan son: planchar, lavar, cocinar, cuidar enfermos o ancianos.

Las mujeres afrocolombianas que trabajan en servicio doméstico, generalmente no son contratadas para desarrollar una sola función específica dentro de los hogares, sino que se contratan para realizar diferentes funciones en una sola jornada laboral. Las funciones más frecuentes son: lavar baños, limpieza de vidrios, sacudir la casa, lavar la cocina, limpiar la 
alacena, jardinería, lavar garajes, preparación de alimentos, sacar a pasear las mascotas, en algunos casos dejar las comidas de la semana preparadas para ser refrigeradas. Al respecto una de las entrevistadas expresó:

El trabajo por días es muy duro. Uno termina rendido porque le toca hacer lo de toda la semana en un día, aparte debe dejar adelantadas las comidas, sobre todo las sopas, para los demás días de la semana que uno no está. Uno no quiere llegar a la casa, porque solo pensar que le toca hacer lo mismo que hizo en el trabajo, y fuera pelear con los hijos para que hagan las tareas es horrible, y se suma pensar que uno tiene que salir a trabajar al otro día a hacer lo mismo en otra casa.

La realidad es que las jornadas de trabajo de muchas mujeres son extenuantes, sobre todo para quienes trabajan por días en donde se agrupan todas las labores del hogar para ser realizadas en una jornada. Situación que se agrava para aquellas mujeres que trabajan todos los días de la semana en distintos hogares, debido a que durante toda la semana se ven enfrentadas a jornadas no solo prolongadas, sino que son jornadas que requieren de mucho esfuerzo físico, mental y emocional.

Las mujeres afrocolombianas que trabajan en el servicio doméstico por días, laboran en hogares ubicados en su mayoría en estrato socioeconómico 3 y 4; aspecto que da cuenta de cómo la sobreexplotación de la mano de obra de estas mujeres, representa una alternativa para el sostenimiento del estatus social de las familias de clase media y media alta de la ciudad de Medellín. Los principales barrios o sectores en donde las mujeres desempeñan su trabajo están ubicados en las zonas noroccidentales y suroccidental de la ciudad. Específicamente en los barrios Laureles, Estadio, Belén, Los Colores, Robledo, Calasanz y La Floresta. Un menor número de participantes (12\%) se encontraban laborando en la zona suroriental de la ciudad en el barrio El Poblado, porcentaje que se debe, entre otros factores, a que existen fundaciones de intermediación laboral ilegal, que se han especializado en suministrar mujeres para el servicio doméstico mínimamente cualificadas y que tengan recomendaciones de casas en El Poblado, de lo contrario no las contratan ${ }^{4}$, lo que agudiza la problemática de la precarización laboral en este sector y que a su vez incide en el mínimo número de trabajadoras afros que tienen la posibilidad de acceder a trabajos en este barrio. En este caso, factores de discriminación como lo son el color de piel, los bajos o nulos niveles de escolaridad y los estigmas culturales acerca de que la población afrocolombiana no es honesta, entre otros, incide para que estas intermediarias ilegales que son usadas por familias de estratos altos les niegue la posibilidad de laborar.

Es de anotar que la jornada laboral de las empleadas del servicio doméstico que trabajan por días o externas, según la reglamentación colombiana se debe acordar por las partes sin que exceda la jornada máxima legal, que siempre es de ocho horas diarias, 48 a la semana, pero que en este tipo de trabajo no se han encontrado los mecanismos para regular estos horarios debido a varios factores, que como se mencionaron al inicio, están en el marco de lo íntimo de los hogares.

\footnotetext{
${ }^{4}$ Este es el caso de la "Fundación San José Empleadas del Hogar" y de otras intermediarias que suministran personal para labores domésticas, según refirieron algunas de las entrevistadas.
} 
Otro aspecto que llama la atención en el caso de las mujeres afrocolombianas que trabajan internas, es que en muchos casos sus hijos los tienen las abuelas o un familiar en sus territorios de origen y por tanto consideran más conveniente ahorrar para poder enviar dinero y garantizar la manutención de su grupo familiar. Argumentan las mujeres que el ser trabajadoras internas representa una forma de "descanso" porque cuentan con todo el día y parte de la noche para realizar las labores para las cuales que fueron contratadas, porque a veces el día no alcanza.

y como a mí me toca es también cuidar a los dos niños, muchas veces cuando uno no termina el oficio del día le toca a uno es madrugar más para alcanzar a hacer todo lo de ese día. Yo me levanto a las 6 y 30 de la mañana, y meestoy acostando a veces a las 11 y media de la noche; y es que a veces me toca hasta escondérmeles porque les coge la llamadera. Trabajar interna significa ser la primera en levantarse y la última en acostarse.

Yo prefiero trabajar interna porque uno por días se mata mucho y la plata no se ve. Desde que trabajo interna he podido ahorrar para comprar mi casita y ando más aliviada porque uno logra adelantar mucha cosa por las noches antes de irse a dormir, además no me gusta trabajar con carangas resucitadas, porque quieren que uno haga todo en un día y además son exigiendo.

Las principales labores que realizan las mujeres que trabajan en el servicio doméstico, independiente de la forma de contratación, son: labores de limpieza 95\%, preparación de alimentos $95 \%$, lavar y planchar $81 \%$, cuidar niños $50 \%$, cuidar ancianos $24 \%$ y cuidar enfermos $21 \%$.

\section{Jornada de trabajo}

En cuanto a la jornada laboral de las mujeres que hacen trabajo doméstico y que laboran bajo la modalidad interna, se encontró que si bien se tiene estipulado que esta no puede ser superior a diez horas diarias de trabajo ${ }^{5}$, el hecho de que no se vengan implementando las visitas de inspección por parte del Ministerio de Trabajo, ni se cuente con otros mecanismos de control que permitan realizar monitoreo al cumplimento de la normatividad laboral, agudizan la cultura de incumplimiento de derechos laborales por parte de los empleadores y de vulneración a derechos de las trabajadoras domésticas, como se muestra en este diagnóstico. Las mujeres afrocolombianas que realizan labores domésticas internas tienen jornadas de trabajo hasta de 18 horas diarias y las que trabajan por días y externas siempre trabajan más de la jornada máxima legal y no reciben ningún recargo adicional por horas de trabajo.

Al respecto se encontró que del $26 \%$ de las mujeres que dijeron trabajar como internas, el 91\% trabajan entre diez y 18 horas diarias, mientras solo el 9\% trabajan hasta diez horas que es su jornada máxima legal (Figura 2).

\footnotetext{
${ }^{5}$ Sustentado en la Sentencia C-372 de 1998 (República de Colombia. Corte Constitucional, 1998).
} 
Figura 2. Horas laboradas en el día por las trabajadoras internas

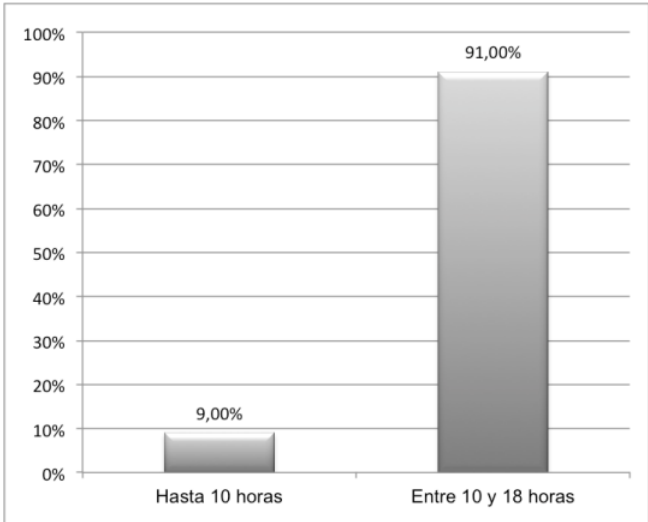

Fuente: elaboración propia.

Del $21 \%$ de las trabajadoras externas encuestadas, el $89 \%$ trabajan entre nueve y diez horas diarias y el $11 \%$ trabaja ocho horas al día, que corresponden a su jornada máxima legal (Figura 3).

Figura 3. Horas laboradas en el día por las trabajadoras externas

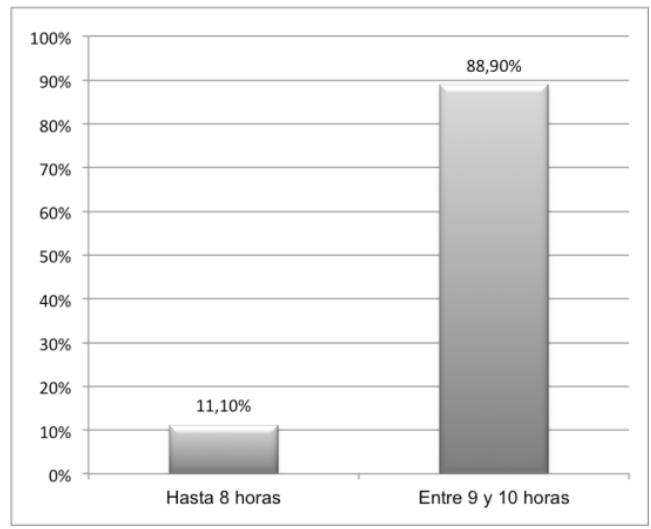

Fuente: elaboración propia.

En el caso de las trabajadoras por días, se tiene que del 52\% de las mujeres trabajan bajo esta modalidad. El $18 \%$ trabajan entre tres y siete horas diarias, el 50\% trabajan entre ocho y diez horas y el $31 \%$ trabajan entre once y catorce horas al día (Figura 4).

Figura 4. Horas laboradas en el día de las trabajadoras por días

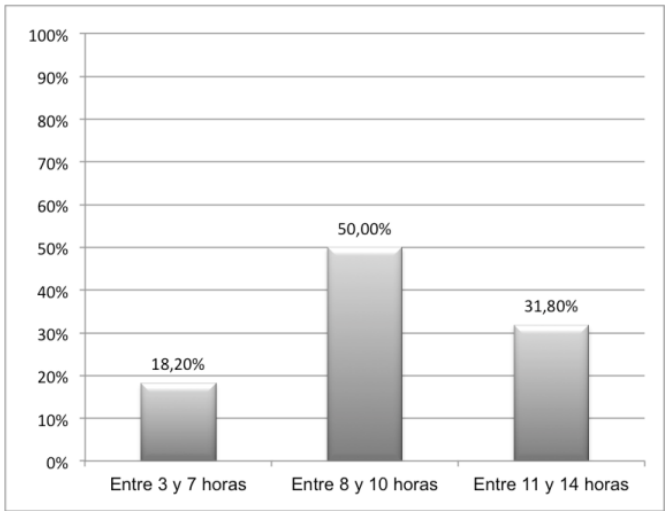

Fuente: elaboración propia. 
Por otro lado, las largas jornadas de trabajo que realizan estas mujeres en sus lugares de trabajo, no les permiten tener otro empleo por fuera de sus hogares, ni mucho menos querer trabajar horas extras. El 81\% de las mujeres manifestó no querer trabajar horas extras en caso de que el empleador se lo proponga, una de las razones son los extensos horarios de trabajo. Las entrevistas manifestaron querer compartir más tiempo con sus familiares y dedicarse al cuidado de sus hijos, además que estas mujeres asimilan las horas extras como las adicionales a las que le toca trabajar porque su empleador se los impuso y que, como se acaba de mostrar, generalmente son horarios superiores a los máximos legales. Adicionalmente a las razones por las que a algunas mujeres no les gustaría trabajar más horas es porque no se las pagan. Solamente el 9\% de las mujeres reciben alguna remuneración por trabajar horas extras y la inmensa mayoría (el 90\%) no recibe ningún pago por este concepto (Figura 5). Algunas mujeres manifestaron que si se las pagaran, podrían considerar trabajarlas para poder compensar los gastos del hogar.

Figura 5. Mujeres que reciben pago por el trabajo de horas extras

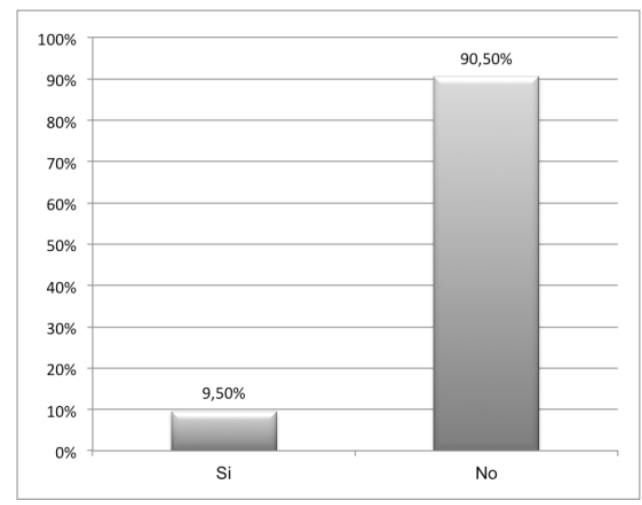

Fuente: elaboración propia.

Sería bueno tener más horas de trabajo para tener otra entradita de plata, pero ya tengo todos los días de la semana y entro a las siete de la mañana y salgo a veces a las ocho de la noche muchas veces. También tengo el sábado comprometido, claro que yo lo quiero dejar ya porque hace un año no me suben y me pagan los mismos veinte cinco mil pesos. Es la patrona donde gano menos y la más exigente (...) yo podía dejar ese sábado para vender mi fritanga que hago más.

Frente al tema de control de jornadas laborales, se encontró que las mujeres mantienen unos mecanismos de control, a través de los cuales se asesoran entre sí cuando sienten que sus derechos están siendo vulnerados. Esta práctica de asesorías laborales se da como un diálogo interno entre mujeres afrodescendientes, quienes también conforman una red de comunicación a través de la cual se recomiendan para nuevos trabajos, se apoyan cuando están desempleadas, se cuentan los conflictos que viven en los hogares en los que trabajan y, desde sus distintas experiencias, buscan una salida a problemas laborales que según dicen ellas no son importantes en otras instancias institucionales que regulan derechos laborales, como lo expresaron algunas de ellas:

Uno va a la Oficina del Trabajo y los abogados no les importa nada. Después uno va y claro ya la patrona se compró al abogado porque no dicen nada. 
Yo fui, traté de conciliar, y allá me dijeron que contratara a un abogado, pero como yo no tenía plata para contratar uno y las cosas se quedaron así. Allá no hacen nada en esas oficinas del trabajo.

\section{Tipo de contrato}

El tipo de contrato más frecuente que se emplea para vincular laboralmente a una persona para la realización de labores domésticas es el verbal. Un porcentaje significativo de las mujeres afrocolombianas que trabajan en servicio doméstico lo hacen bajo esta modalidad con un $85 \%$. El $12 \%$ las contratan por medio de un contrato escrito y un $2 \%$ no sabe bajo que modalidad se encuentra contratada (Figura 6). Un aspecto que llamó la atención durante la recolección de información, es el hecho que algunas mujeres consideran que a través de un contrato verbal, sus empleadores no están obligados a cubrir prestaciones sociales. Igualmente, algunas mujeres asumen que con este tipo de contrato no tiene derecho a que se les suministre calzado y vestido para desempeñar las labores para las cuales fueron contratadas, como lo expresó una participante:

La verdad es que yo los iba a demandar por la plata, pero yo no teníafirmado con ellos nada en los cuatro años que les trabajé, por eso no podía ponerme a exigir tanto, claro que arreglamos y no demandé nada. Mis amigas dicen que yo soy muy boba porque sí tenía derecho. Hasta que me dieran los delantales, yo llevaba siempre mi sudadera para hacer el oficio.

Figura 6. Tipo de contrato

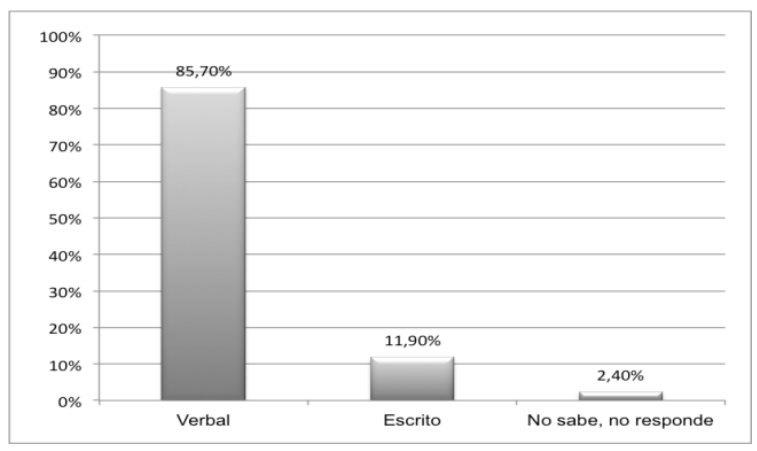

Fuente: elaboración propia.

Con relación a si las mujeres estaban satisfechas con el tipo de contrato que tenían, un porcentaje del 59\% manifestó estar satisfecha con el tipo de contrato verbal. Al momento de indagar por las razones de satisfacción con el tipo de contrato, estas argumentan que es mucho mejor no tener un contrato por escrito para no tener compromisos y cuando ellas consigan un mejor empleo se pueden marchar, debido a que así no generan compromisos con sus empleadores o empleadoras. Las mujeres además expresan que no aspiran a permanecer siempre en este trabajo. Esta situación devela el desconocimiento, por parte de la población encuestada, de las implicaciones legales de un contrato de trabajo verbal, escenario que es aprovechado por los empleadores para justificar el no pago de prestaciones sociales, la no afiliación a la seguridad social y desconocer la estabilidad laboral de la trabajadora.

Otro porcentaje de mujeres correspondiente al 38\%, dice no estar satisfechas con el tipo de contrato al sentir que la forma de contratación permite que se generen algunos abusos por parte de sus empleadores como por ejemplo: que las despidan sin tener que pagar indemnizaciones 
por despido injusto, que no puedan pedir permisos ni en casos de calamidad doméstica y, sobre todo, que tengan que realizar labores por fuera del hogar para las que fueron contratadas. También se encontró que un $16 \%$ de las mujeres que trabajan en servicio doméstico son contratadas para realizar funciones en varios sitios diferentes al hogar para el cual las contrataron. Al profundizar frente al tema se encontró que estas mujeres son trasladadas con frecuencia por sus patrones o empleadores a otros negocios familiares a realizar labores de limpieza como, por ejemplo, en almacenes, galerías, tiendas y restaurantes en donde realizan, en ocasiones, el total de la jornada laboral, pero no reciben ningún otro pago ni beneficio por esta actividad.

A veces mi patrón me llevaba a su restaurante a cocinar y hacer aseo una vez por semana, como les ha gustado lo que hago allá y la forma como cocino, ahora me dio dos días de trabajo en el restaurante y tengo tres días en la casa de la esposa (...) claro que no tengo otro contrato, sino que me paga igual que en la casa, por día trabajado pero eso me sirve de experiencia.

\section{Ingresos mensuales y prestaciones sociales}

Establecer los salarios de las empleadas domésticas en Medellín resulta bastante complejo, sobre todo si se tiene en cuenta que una mayoría de estas laboran por días. Aspecto que hace que en el medio se tenga en promedio varias tarifas que oscilan entre los $\$ 20.000$ y $\$ 35.000$ diarios. Al respecto una de las entrevistadas dice:

Yo solo tengo dos días porque en otras casas no me pagan lo que pido. Yo no trabajo mi día por menos de treinta y cinco mil pesos y además me tienen que dar ellos mis pasajes porque entro a las 7 de la mañana y salgo muchas veces a las ocho de la noche, además no me tienen que pagar nada de prestaciones, ni el seguro porque yo tengo mi SISBEN ${ }^{6}$.

Igualmente, para las que trabajan internas resulta toda una aventura establecer cuánto realmente ganan por una semana de trabajo. Las razones obedecen, según lo mostraron las entrevistas, a que no hay en el medio una cifra exacta sobre cuánto cobrar como lo comentan las mujeres: "Los empleos en donde se gana más del salario mínimo están cada día más escasos". El promedio de ingresos mensuales de la mayoría de las mujeres que trabajan en el servicio doméstico en Medellín está por debajo del salario mínimo mensual legal vigente como se muestra en los datos. Se encontró que solo un $12 \%$ gana más de $\$ 566.000$ mensuales. Otro grupo mayoritario de mujeres equivalente al 62\% tiene ingresos mensuales entre $\$ 301.000$ a $\$ 566.000$, el $21 \%$ recibe entre $\$ 151.0000$ y $\$ 300.000$, las demás mujeres que se dedican a esta labor tienen unos ingresos mensuales inferiores a $\$ 150.000$. El $85 \%$ de las mujeres encuestadas ganan menos del salario mínimo legal para el año 2012.

En cuanto al suministro de calzado y vestido de labor al que tienen derecho las trabajadoras domésticas indistintamente de la modalidad en la que trabajen, al $40 \%$ de las mujeres, su empleador no se los suministra, mientras el 57\% respondió que sí. Sin embargo, es de aclarar que muchas de las mujeres que respondieron que sí, en las entrevistas manifestaron que a ellas

${ }^{6}$ El Sisben es el Sistema de Identificación de Potenciales Beneficiarios de Programas Sociales, administrado por el Departamento Nacional de Planeación DNP. Entre los programas a los que provee acceso se encuentra la Seguridad Social en Salud en el marco del régimen subsidiado (SISBEN, s.f). 
les daban vestimenta como parte del salario en especie, situación que deja en claro que para algunas trabajadoras domésticas el pago en especie de vestimenta y la obligación que tiene el empleador de proveer el calzado y vestido de labor son lo mismo o lo tratan indistintamente.

Por otro lado, con relación a si lo percibido en salarios y prestaciones era suficiente para cubrir la totalidad de los gastos del hogar, durante el desarrollo de las entrevistas y en los grupos focales, fue frecuente escuchar a las mujeres decir que sus ingresos no les alcanzaban para cubrir los gastos del hogar, razón por la cual a muchas de ellas les toca hacer otras actividades durante el día sábado en las noches, especialmente los domingos, en sus hogares, como por ejemplo vender comidas. Aspecto que da cuenta de que existen unas necesidades básicas insatisfechas, pues la remuneración recibida no les alcanza para cubrir el sostenimiento de los gastos de alimentación, vivienda y servicios públicos del hogar, como lo expresa el $66 \%$ de las mujeres, que dijo no alcanzarle el dinero.

Pese a que a las mujeres afrocolombianas que viven en la ciudad de Medellín y que trabajan como empleadas del servicio doméstico no les alcanza el dinero para cubrir los gastos básicos del hogar, un porcentaje del $78 \%$ responde no tener un segundo trabajo que le genere ingresos adicionales. Ahora, el $21 \%$ de las mujeres afrocolombianas que trabajan en el servicio doméstico en Medellín tienen un segundo trabajo. Esto lo hacen para cubrir gastos de sostenimiento del hogar (55\%), complementar sus ingresos (44\%) y para entretenimiento (22\%). Un aspecto que llama la atención es que algunas de las mujeres no consideran las labores de ventas de comidas que realizan los fines de semana en sus casas como un segundo trabajo, al no tener un patrono a quien darle cuentas de sus actividades, ni tener que cumplir horarios.

Además, existe un bajo nivel de satisfacción con el empleo que tienen las mujeres que trabajan en servicios domésticos en la ciudad de Medellín, en tanto los ingresos percibidos por concepto de prestaciones sociales son irrisorios o no se las pagan. Al respecto el $47 \%$ recibe dinero por concepto de vacaciones, al 19\% de las mujeres les pagan primas y solo el 33\% recibe algún dinero por cesantías (Figura 7).

Figura 7. Remuneración que reciben las personas trabajadoras domésticas

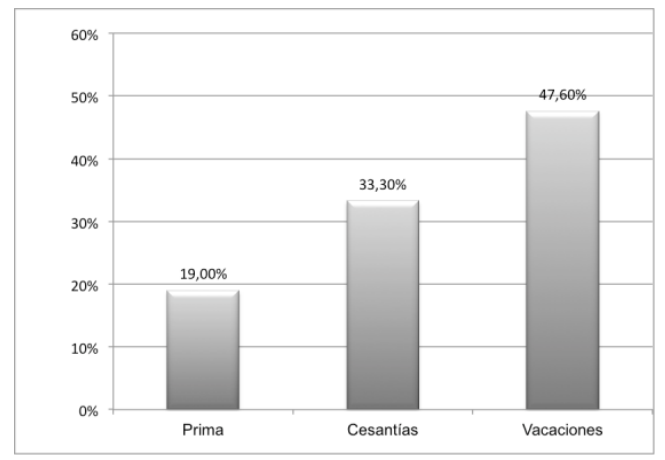

Fuente: elaboración propia.

En esta misma línea, del 33\% de las mujeres que les pagan cesantías, un porcentaje significativo del $64 \%$ no está afiliada a ningún fondo de cesantías; no obstante, trabajan de forma permanente y continua con uno o más empleadores. Un $12 \%$ no sabe si está afiliada y solo el $23 \%$ de las mujeres se encuentran afiliadas a algún fondo de cesantías. Solo un $16 \%$ de ellas dice saber a cuánto equivale el valor que se le debe pagar anualmente por este concepto y cuál es el fondo 
donde se las consignan. El 83\% les pagan las cesantías, pero no saben cuánto deberían recibir por este concepto, situación que es aprovechada por los empleadores para pagar por debajo de lo legalmente estipulado como pago de cesantías.

Como se acaba de indicar, las mujeres no ganan en su mayoría ni un salario mínimo, la mayoría de ellas no tiene un segundo trabajo para cubrir la totalidad de los gastos del hogar, un alto número de mujeres no reciben pago por concepto de prestaciones sociales y las que reciben no saben si les están pagando dentro de los márgenes legales. Esta situación de precarización laboral lleva a que las mujeres afrocolombianas trabajadoras domésticas tengan restringidas posibilidades de estudiar, salir de la pobreza y ascender laboralmente, convirtiéndose esta situación en un círculo vicioso donde el trabajo doméstico trasciende de generación en generación.

\section{Nivel de satisfacción con el empleo}

Las mujeres afrocolombianas trabajadoras domésticas de la ciudad de Medellín no están satisfechas con sus trabajos. Un porcentaje mayoritario correspondiente al $50 \%$ de las encuestadas, dijo no estar nada satisfechas y poco satisfechas con sus actuales trabajos. El 57\% no están satisfechas con lo que gana, el $26 \%$ con la aplicación de conocimientos, el $62 \%$ con los beneficios y prestaciones que recibe, el $57 \%$ con la jornada laboral y el $21 \%$ no están satisfechas con la aplicación de sus saberes culturales y ancestrales. Un 76\% responden que les gustaría cambiar de trabajo, argumentando varios motivos como se menciona a continuación: el $48 \%$ dice que quiere cambiar de trabajo para mejorar la utilización de sus capacidades o formación.

Este aspecto está estrechamente relacionado con la experiencia que muchas de estas mujeres tienen en temas específicos propios de su cosmovisión, como la preparación de alimentos y cuidado de enfermos con plantas medicinales. Otra de las razones tiene que ver con la necesidad de trabajar menos horas para poder criar a sus hijos y poder compartir más con sus familias. En este sentido, el $45 \%$ de las mujeres respondió que debido a lo largo de sus jornadas de trabajo les gustaría trabajar en otros lugares. Entre los lugares que mencionan les gustaría trabajar, se encuentran almacenes, restaurantes y fábricas. Sin embargo, pese a que manifiestan que en estos lugares el trabajo es muy duro, la ventaja es que al menos contarían con una hora exacta de entrada y de salida, lo que les permitiría compartir con sus familias los días domingos y festivos.

Por otro lado, no hay satisfacción con el trabajo que realizan porque sienten que no las tratan como personas, porque existe un estigma o una subvaloración con la trabajadora del servicio doméstico, razón por la cual en ocasiones se avergüenzan de decir a qué se dedican.

Yo digo: ay Dios mío yo no sé por qué estoy acá, me gustaría estar en otra parte. Porque uno no escoge lo que uno quiere, sino lo que le toca. Dios mío a veces digo, ojalá me pudiera ganar el chance y no estar acá, me aterra de verdad, uno se siente aprisionado allá, como que uno no encaja. Saber que todo el mundo está afuera y uno está encerrado sin quererlo, realmente a mí me hace sentir mal. No me gusta ni hablar de eso y me pone muy triste.

Igualmente, algunas mujeres expresaron que el motivo de no estar satisfechas con su trabajo es porque que les toca sortear al interior de los hogares en donde trabajan con diferentes tensiones para ganarse el respeto de algunos integrantes de la familia para la que trabajan, en donde se 
presentan abusos sexuales y maltratos psicológicos al tener que soportar frases racistas y sortear hasta algunas pruebas que les dejan las patronas para saber si son honradas.

A mí me han dejado plata y anillos por ahí tirados, debajo de las camas, la mesas, en la mesa de la pieza y todo pa' ver si yo las cojo. Uno nota que es una trampa porque ve que en la noche la llegan buscando y todos le preguntan por las cosas y lo miran a uno, pero uno sabes que uno es honrado y que es para ver si uno es ladrón.

Otro motivo de insatisfacción con el trabajo de las mujeres que trabajan en servicio doméstico lo constituye el hecho de tener que dejar a sus hijos al cuidado de otras personas extrañas, parientes y vecinos por todo un día y, en ocasiones, hasta toda una semana. Estas mujeres no pueden muchas veces vivir con sus hijos y los dejan al cuidado de las abuelas, familiares cercanos o "paisanos" en sus territorios de origen. Los aspectos anteriores explican por qué a un alto porcentaje del $76 \%$ de las mujeres les gustaría cambiar de trabajo.

Otro aspecto por el cual dicen las mujeres que laboran en servicio doméstico que les gustaría cambiar de trabajo, está relacionado con el esfuerzo físico que este les exige, puesto que permanentemente están cansadas. Este aspecto puede estar relacionado, como se mencionó antes, con la cantidad de labores que se agrupan para ser realizadas en un día o dos días de trabajo para el caso de las que trabajan externas o por días, así como con las jornadas de trabajo nocturna que deben hacer muchas de las mujeres que laboran bajo la modalidad de internas. Otro porcentaje alto de mujeres, el 66\%, dice que el motivo de querer cambiar de empleo es para mejorar los ingresos, debido a que este no alcanza para la manutención de sus grupos familiares. Por último, otras mujeres dicen querer cambiar de trabajo porque sienten que el cambiar este oficio de trabajo doméstico por el trabajo en restaurantes, peluquerías o ventas ambulantes, entre otros, constituye una forma de asenso laboral.

\section{Seguridad social y salud}

La calidad del servicio y la cobertura son los principales problemas en el acceso a la seguridad social y el asunto es más complejo cuando se habla de régimen subsidiado. La inequidad social tiene un lugar importante en esta situación en tanto la salud se ha convertido en una herramienta de exclusión donde el desconocimiento de los derechos en este aspecto y la ausencia de herramientas para exigirlos aumentan la problemática de acceso a la salud. Sin embargo y sin creerlo posible, el escenario para las trabajadoras domésticas es aún peor, dado que, por la particularidad de algunas formas de la prestación del servicio, como lo es el que se hace por días, el acceso es negado.

Por decir, una madre cabeza de familia puede tener dos, tres días en la semana en las actividades realizadas en una casa de familia ganándose 20, 25 o 30 mil pesos. De esos 30 mil o menos yo tengo que sacar lo que es el transporte, a mí no me dan un seguro en una casa de familia. Cuánto me cuesta a mí un seguro en cuanto a la parte de seguridad social, que con lo que yo me estoy ganando no me da porque es que la patrona a donde voy ese día de trabajo, que por qué voy un solo día no tengo derecho a seguridad social.

En cuanto a la afiliación a la salud, fue frecuente escuchar durante todo el proceso de diagnóstico frases como: 
Yo no dejo que mi patrona me afilie a salud, porque pierdo mi SISBEN.

Ella y yo pactamos que me pagaba un poquito más por el día de trabajo porque yo ya tenía SISBEN.

Las vueltas para que le vuelva a dar a uno el SISBEN son muchas y yo no puedo dejar a mis hijos sin salud, así que le dije que le trabajaba, pero si no me hace salir de mi SISBEN.

Expresiones como las anteriores muestran el desconocimiento y el temor que existe entre las mujeres que trabajan en el servicio doméstico de quedar desprotegidas por el sistema de salud, ante lo que aceptan realizar contratos que no incluyan este derecho. En esta medida, se encontró que solo el $23 \%$ de las mujeres están afiliadas a una entidad de seguridad social en salud de las cuales solo el $40 \%$ son cotizantes. Por otro lado, un $7 \%$ de las mujeres pagan el total de afiliación. El 55\% son beneficiarias, el 14\% está en el régimen subsidiado (ARS) y el 35\% no sabe si está afiliada a salud.

Una de las razones para que exista un porcentaje tan bajo de mujeres empleadas del servicio doméstico que cotizan en el sistema de seguridad social en salud, está relacionado, como se mencionó anteriormente, con factores como temor de quedar por fuera de sistema de salud si se salen del SISBEN, sobre todo para el caso de las que trabajan por días o externas porque sus patrones no pagan:

Es muy difícil que me paguen porque en la semana trabajo en tres casas distintas y son barrios muy distintos. Ellas no se conocen para pagarme entre todas. Claro que cada que me enfermo ellas me colaboran con la droga y los pasajes y además no necesito porque cada que me enfermo voy al médico con el SISBEN.

\section{Seguridad social en pensiones}

Otro factor alarmante frente a las condiciones laborales de las mujeres que trabajan en el servicio doméstico en Medellín, lo representa el bajo porcentaje (19\%) de las que están afiliadas a un fondo de pensiones. El 69\% de las trabajadoras no están afiliadas, el $9 \%$ no sabe si lo está. En este aspecto se encuentra un desconocimiento por parte de las mujeres del servicio doméstico sobre sus derechos laborales, aspecto que se evidenció cuando se les preguntó al $81 \%$ que no está afiliada al fondo de pensiones por los motivos de no afiliación. Entre las razones que dieron las mujeres se encuentran: que no tiene dinero para pagar (41\%), no saben cómo afiliarse (10\%) y no se lo exige su empleador (7\%). Para el $20 \%$ su empleador no paga la parte que le corresponde y el mismo porcentaje no sabe o no responde.

\section{Afiliación al sistema de riesgos profesionales}

Al igual que en salud y pensión, se cuenta con un porcentaje bajo de mujeres que dice estar afiliadas a riesgos profesionales con un $14 \%$. Estas dicen que su empleador lo tiene afiliado a una ARL (Figura 8). 
Figura 8. Niveles de afiliación al sistema de riesgos profesionales

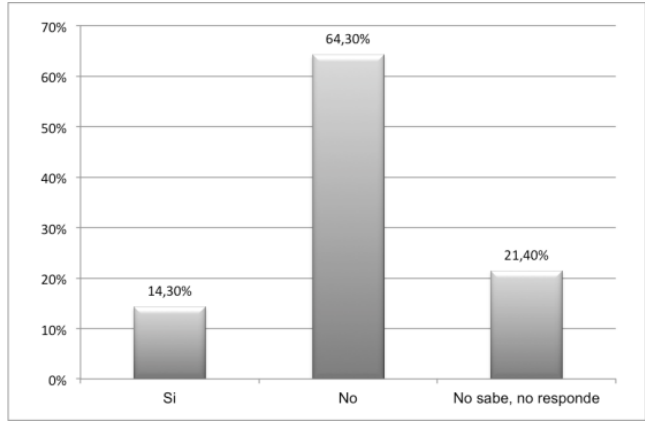

Fuente: elaboración propia.

\section{Accidentes y enfermedades por el trabajo}

En cuanto a la seguridad laboral, se encontró que las mujeres, en un porcentaje del 28\%, han tenido accidentes en sus lugares de trabajo. Los accidentes más frecuentes son: golpes contra objetos, cortaduras, quemaduras, fracturas y heridas por causa de mascotas. El $64 \%$ dice no haber tenido accidentes en sus lugares de trabajo. El $43 \%$ de las mujeres ha contraído enfermedades producto de su trabajo, siendo más frecuentes las enfermedades respiratorias, musculares o de las articulaciones, enfermedades de la piel, enfermedades psicológicas, enfermedades de la columna e intoxicaciones. Las mujeres expresan que las causas de estas enfermedades están relacionadas con el manejo de químicos que se emplean para la limpieza (límpido, detergentes, amoniaco); al hecho de tenerse que mojar acaloradas luego de planchar y por correr y levantar permanentemente objetos pesados del hogar.

De las entrevistas realizadas, se evidencia que el porcentaje de trabajadoras que dicen haber estado incapacitadas corresponde al número ínfimo de mujeres que están afiliadas a la seguridad social en salud, por esta razón aseguran que la incapacidad es pagada por el empleador en tanto es el sistema de salud quien finalmente le da el dinero al empleador y este se lo hace llegar a la trabajadora; sin embargo, no se puede perder de vista que existe un gran porcentaje de mujeres que pudieron estar incapacitadas para trabajar pero al no estar afiliadas al sistema, ellas no las perciben como incapacidades en tanto el empleador no se las paga y lo que sucede en la práctica es que ese día la trabajadora manifiesta no poder ir a trabajar y en consecuencia no hay pago.

\section{Las luchas de UTRASD: reivindicaciones, logros y retos}

En marzo de 2013 nació en Medellín la Unión de Trabajadoras del Servicio Doméstico UTRASD, con 28 mujeres y que hoy cuenta con cerca de 200 afiliadas. UTRASD nace como producto de esta investigación para conocer la situación de las mujeres afro en Medellín, en su gran mayoría empleadas domésticas $\mathrm{y}$, por tanto, la composición del sindicato es mayoritariamente de afrodescendientes, pero también está integrado por mujeres blancas, mestizas e indígenas. Su misión es velar por los derechos laborales de las empleadas domésticas en general, lo que implica también trabajar contra la discriminación racial y de género. Esta iniciativa ha sido apoyada por la Escuela Nacional Sindical (ENS), Carabantú y por Hablemos de Empleadas Domésticas. La ENS les ha suministrado asesoría jurídica en su constitución, formación en derechos humanos, laborales y sindicales a las empleadas y suministro de la logística para el funcionamiento del mismo. Del movimiento ciudadano han recibido apoyo en comunicaciones para su visibilización y posicionamiento a través de las redes sociales digitales y eventos académicos. 
El sindicato UTRASD (Figura 9) es en este momento la organización más activa con que cuentan las trabajadoras domésticas remuneradas en Colombia. Las empleadas se reúnen semanalmente en la ENS, y su Junta Directiva viene siendo apoyada por la Central Unitaria de Trabajadores- CUT. Allí reciben capacitaciones y delimitan consensuadamente su plan de trabajo.

Figura 9. Fundación del sindicato 2013
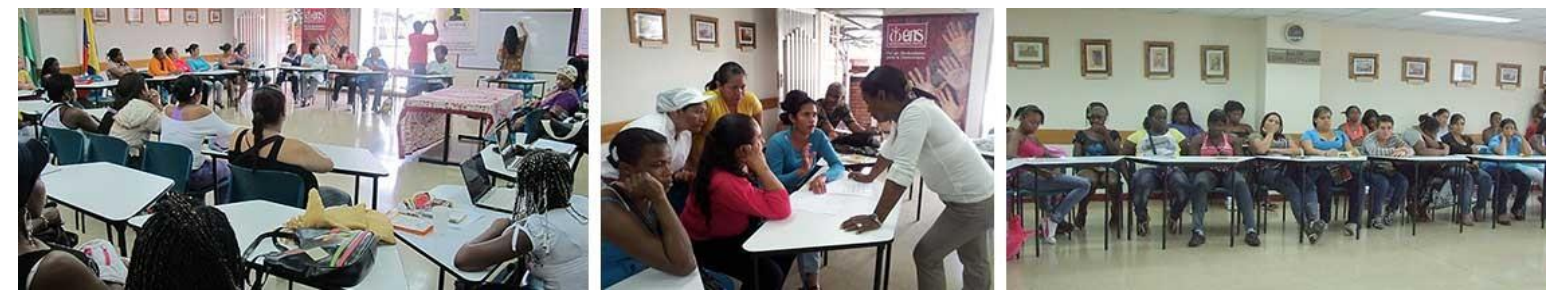

Fuente: Archivo fotográfico del sindicato.

La lucha, movilización y resistencia han sido el común denominador de las mujeres afrocolombianas de Medellín que dieron origen a esta expresión sindical única en el país, no solo por ser una organización de trabajadoras domésticas, sino porque su base son las luchas contra la discriminación racial y de género.

Este grupo de mujeres empieza dando sus primeros pasos con tres reivindicaciones bandera que aún se mantienen y que son la columna vertebral de sus luchas: I) La reivindicación por un trabajo decente en condiciones de igualdad. II) La lucha contra la discriminación racial y de género. III) La reivindicación por la dignificación del trabajo doméstico y revaloralización de su aporte a la construcción de sociedad.

Son sus banderas las que las han llevado desde el año 2013, a direccionar su plan de acción en cinco ejes: I) La necesidad de llegar a más mujeres, creciendo como organización sindical. II) Formar y fortalecer a sus bases desde la construcción de liderazgos fuertes para la incidencia. III) Visibilizando y comunicando cada una de sus acciones desde lo colectivo, dirigiendo mensajes claves a los distintos actores del mundo del trabajo, medios de comunicación, políticos y actores gubernamentales tomadores de decisión, empleadores y sociedad en general. IV) Generando evidencia a partir de investigaciones que develen las condiciones laborales y de discriminación de las mujeres trabajadoras domésticas afrocolombianas y en general. V) Dirigiendo acciones desde la defensa a los derechos vulnerados de las trabajadoras domésticas desde la protección y restablecimiento de los derechos. Estos cinco ejes en la actualidad se mantienen vigentes en la organización sindical y han logrado materializarse. Tanto, que a la fecha UTRASD cuenta con seis subdirectivas en Medellín, Bogotá, Buenaventura, Cartagena, Huila y Urabá, las cuales han logrado posicionarse en la agenda nacional e internacional, en los medios de comunicación como un sindicato que reivindica los derechos de las trabajadoras domésticas.

Como un reconocimiento a la particular iniciativa de crear un sindicato de mujeres trabajadoras domésticas afro, María Roa como presidenta de UTRASD en mayo de 2015 fue invitada a hablar de su experiencia personal como trabajadora doméstica y del sindicato en la Universidad de Harvard (Figura 10) en el mismo salón que el filósofo Noam Chomsky, y en diciembre del mismo año fue seleccionada como una de las veinte líderes más importantes del país por la Revista Semana y la Fundación Liderazgo y Democracia. 
Figura 10. María Roa Borja durante visita a la Universidad de Harvard, 2015

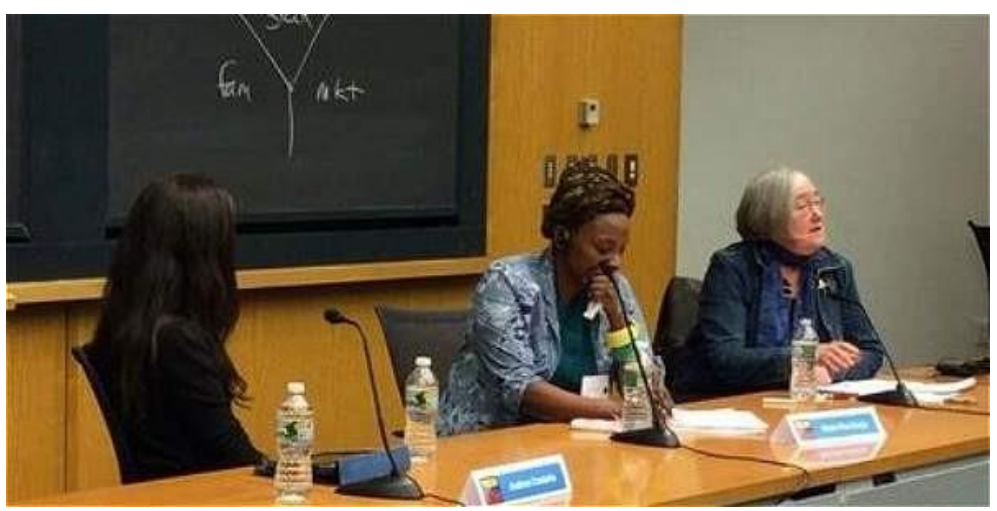

Fuente: El Tiempo (2015).

Durante su discurso en Harvard, María Roa Borja compartió mesa con Jane Halley, académica de la escuela de Leyes de esa institución. Así mismo, la presidenta de UTRASD como representante de un sindicato que tiene clara su apuesta de incidencia en políticas públicas, logró poner el debate sobre la necesidad de otorgarle el derecho a primas de servicios a las trabajadoras domésticas de todo el país, las cuales históricamente eran excluidas del reconocimiento y pago de esta prestación a la que tenían derecho todos y todas las trabajadoras excepto este sector. Este cabildeo ante el Congreso de la República y otros actores dio como resultado la expedición de la Ley 1788 de 2016 con la cual ya todas las trabajadoras domésticas de Colombia tendrían derecho a esta prestación; en esta ley UTRASD jugó un papel muy importante que llevó al desmonte de una norma abiertamente discriminatoria.

En este sentido, en junio del año 2016 el Congreso de la República de Colombia aprobó la ley que ordena el pago de la prima de servicios a las trabajadoras domésticas, después de 66 años de discriminación, cambiando así una norma que desde el año 1950 les negaba este derecho a las trabajadoras domésticas remuneradas (Figura 11). Los medios de comunicación registraron el momento histórico:

Estamos felices por la aprobación de esta ley de la prima salarial. Ha sido un proceso muy lindo, porque desde muchas partes hemos aportado para este logro, señaló María Roa Borja, presidenta de Unión de Trabajadoras Afro del Servicio Doméstico, Utrasd, sindicato que abanderó la conquista de este derecho para las 750 mil mujeres que, según el DANE, laboran en el servicio del hogar. Aunque por el sub-registro se estima que son más de un millón. Esta ley tiene un impacto no solo económico sino también social muy significativo. Es un avance hacia la dignificación del trabajo doméstico, con impacto redistributivo para cerca de 800 mil mujeres, y que se hace extensivo a jardineros, mayordomos y personas que trabajan en fincas y haciendas, dijo Ángela María Robledo, del Partido Verde, quien, junto con Angélica Lozano, del mismo partido, impulsaron la iniciativa en el Congreso (ENS, 2016). 
Figura 11. Presencia de trabajadoras domésticas se hizo sentir en el Congreso

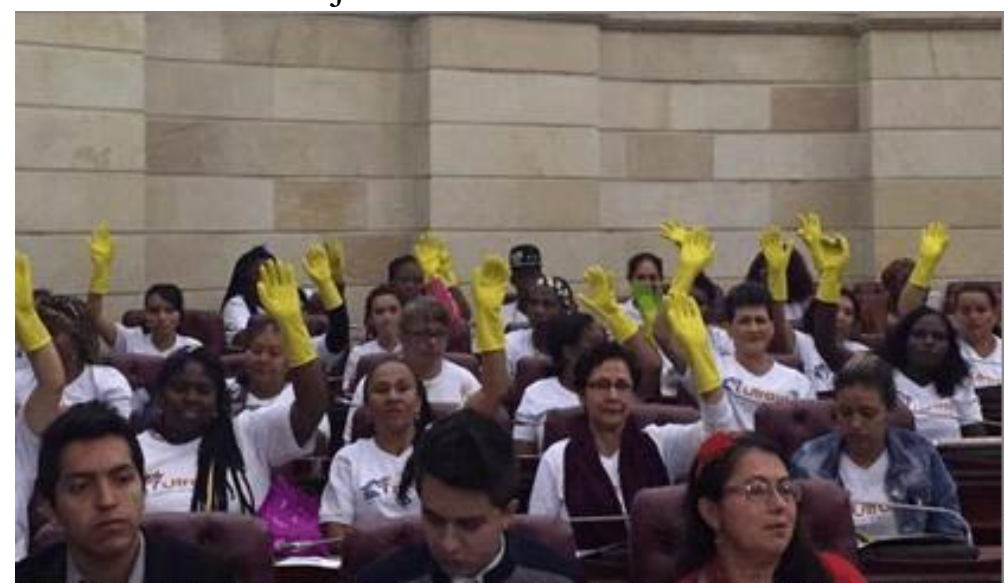

Fuente: ENS (2016).

La parlamentaria destacó esta ley como un logro colectivo, pues contó con la aprobación de todos los partidos políticos representados en el Congreso de la República, y el aporte de UTRASD y otros sindicatos, varias organizaciones sociales y de mujeres, instituciones del Estado, medios de comunicación y la Escuela Nacional Sindical. Así que a partir de ahora las trabajadoras domésticas recibirán un sueldo adicional por concepto de prima, la mitad en junio y el resto en diciembre (Figura 12). Y las que trabajan por días en los hogares también tienen derecho a la prima. A éstas cada empleador debe pagarles la parte que proporcionalmente les corresponda.

Figura 12. En el Congreso de la Republica después de la aprobación de la ley de primas

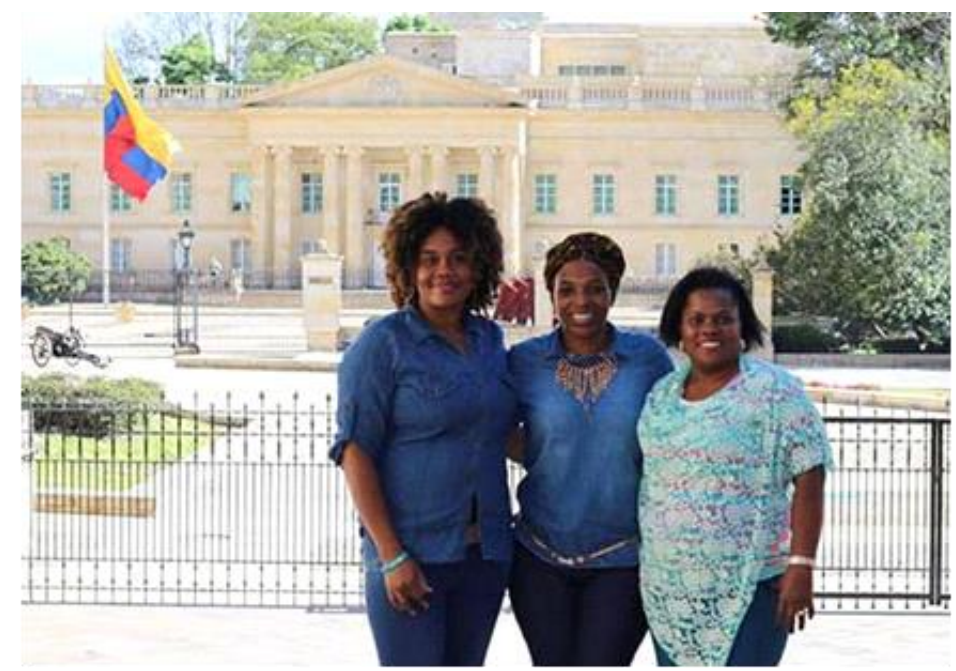

Nota: De izquierda a derecha, Claribed Palacios, secretaria Utrasd; María Roa presidenta; Flora Inés Perea, vicepresidenta.

Fuente: ENS (2016).

Como antecedentes legales de esta ley de prima de servicios, están la Ley 1413 de 2010 de Economía del Cuidado, que midió la contribución de la mujer a la economía nacional mediante su trabajo en el hogar; el Convenio 189 de OIT sobre trabajadoras y trabajadores domésticos, aprobado el 16 de junio de 2011, a la luz del cual el Congreso de Colombia aprobó en 2012 la Ley 1595, ley de trabajadoras domésticas. En 2014 la Corte Constitucional expidió la importante sentencia C-871, que exhorta al Congreso a corregir la discriminación laboral contra 
las empleadas domésticas y pide garantizarles la prima de servicios, toda vez que reconoce el hogar como unidad económica productiva, y por tanto las domésticas tienen derecho al pago de prima de servicios.

Pero el cabildeo ante el Congreso de la República es solo uno de los escenarios en los que incide UTRASD. En la actualidad, también ha logrado incidir en la creación y viene participando en la subcomisión de seguimiento al cumplimiento del convenio 189 de la OIT, creada por el Ministerio de Trabajo y desde el cual se tiene un plan dirigido a la formulación de una política pública de trabajo decente para el sector del trabajo doméstico. Por esto en octubre de 2017 ante la Comisión Séptima de la Cámara de Representantes, el Ministerio de Trabajo rindió cuentas a las lideresas sindicales de las trabajadoras domésticas del país, para exponer los avances y retos del Gobierno en materia de formalización para este sector y para reanudar las reuniones tripartitas de la subcomisión de seguimiento al Convenio 189 (Figura 13). A la fecha se han realizado tres reuniones, la última de ellas en marzo del año 2018 donde el punto principal de discusión fue la problemática de implementación real del Convenio y la participación del Ministerio de Trabajo y de UTRASD en la Conferencia \# 107 de la OIT en la comisión de violencia y acoso en el trabajo para la adopción de un nuevo convenio y recomendación sobre este tema.

Figura 13. UTRASD y el Ministerio de Trabajo, en la evaluación de avances de las políticas del sector de las trabajadoras domésticas

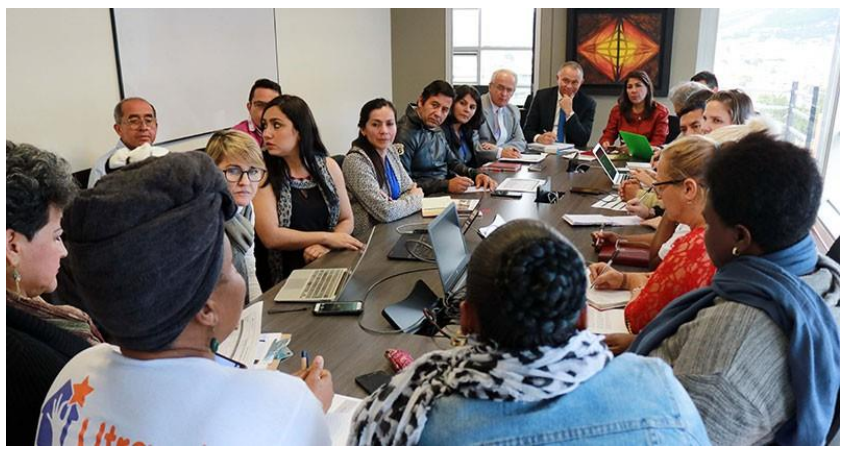

Fuente: Ministerio del Trabajo (2017).

Adicionalmente, en lo que tiene que ver con sumarse a otras estructuras sindicales del trabajo doméstico y aunar fuerzas, en octubre de 2016 y con la realización del Encuentro Nacional de Trabajadoras Domésticas, se creó el espacio intersindical de articulación entre los sindicatos de trabajadoras domésticas remuneradas existentes en Colombia, conformado por SINTRAIMAGRA, SINTRASEDOM, UTRASD y ASOHOGAR. A la fecha este espacio de articulación logra generar sinergias entorno a una agenda intersindical común, que tiene como único propósito la reivindicación de los derechos de las trabajadoras domésticas en el país.

Ahora bien, son muchos los retos que UTRASD tiene, pero de los más relevantes y prioritarios son el continuar con el desmonte de normas que discriminan y no atienden a las particularidades del sector, como por ejemplo el artículo 162 del Código Sustantivo del Trabajo que establece la jornada máxima laboral para las trabajadoras domésticas internas de diez horas, mientras para el resto de los y las trabajadoras del país es de ocho horas diarias. Otro de los retos es incidir en un tratamiento preferencial de las mujeres que laboran en este sector desde el acceso a las instituciones y a la justicia que promuevan una cultura de denuncia por parte de las mujeres, 
que ayuden a la identificación de problemáticas con miras a la búsqueda de respuestas estructurales desde el Estado y desde la sociedad.

UTRASD también ha ubicado sus retos en centrar debates importantes como la necesidad de tener una clasificación específica del sector en el sistema de riesgos laborales y de poner de presente que cuando los lugares de trabajo son los hogares, los riesgos a la salud, la vida, la seguridad y la exposición al acoso y a la violencia son más altos y requieren enfoques de prevención y protección particulares y distintos a las que se tienen para los demás lugares de trabajo que generalmente tienen menos exposición. Por esta razón, una de las prioridades de esta organización sindical es responder al actual contexto nacional e internacional de cara al nuevo Convenio y Recomendación de la OIT sobre acoso y violencia en el lugar de trabajo, incidiendo para que estos instrumentos logren responder a las necesidades de prevención y protección del sector del trabajo doméstico.

Estas son algunas de los logros, retos y reivindicaciones de esta organización sindical que ha logrado en corto tiempo posicionarse como un sindicato con un norte claro y con muchas posibilidades de generar transformaciones en el país y de participar activamente de los cambios a nivel regional y global que desde el mundo del trabajo se dan.

\section{Conclusiones}

Como se mostró en el diagnóstico, las condiciones que hoy viven las mujeres afrocolombianas que se dedican al trabajo doméstico en Medellín, muestran datos alarmantes que dan cuentade cómo sus derechos se han venido vulnerando y cómo este oficio se encuentra por fuera de los estándares de la legislación laboral. La falta de oportunidades laborales y la impetuosa ciudad paisa se convierten en un sueño de esperanzas para mejorar las condiciones de vida y forjar familias en mejores condiciones económicas, lo que estas mujeres desconocen es que la cultura paisa ve a la mujer afro como una muy buena opción para la crianza, la alimentación, el cuidado y la manutención de sus hogares y sus hijos, pero no para otro tipo de trabajos, pues en el imaginario rondan las ideas de que la mujer afro cocina de muy buen sabor, son fuertes y "necesita el trabajo". Es así como en las periferias de Medellín poco a poco se han venido concentrando mujeres que por su color de piel sufren una profunda discriminación laboral en tanto el mercado las enmarca en el trabajo doméstico como la única posibilidad laboral. Además, son mujeres que por efecto del desplazamiento no han podido terminar sus estudios, alineado a una infalible cadena de pobreza y a los problemas mismos de deslaboralización y precarización laboral del trabajo doméstico.

Son estas algunas de las razones por las que varias mujeres afro de esta ciudad decidieron organizarse en un sindicato para reivindicar derechos laborales como mujeres, queriendo visibilizar la problemática desde la óptica laboral y desde la discriminación racial en el trabajo. Serán estas transformaciones a partir de colectivos de mujeres que extraigan de las cuatro paredes del hogar a las mujeres trabajadoras domésticas, para que se reivindiquen como sujetos de derechos laborales en la esfera de lo público y lo productivo. Es posible concluir a partir de esta investigación que se puede llegar al empoderamiento de colectivos que participan activamente en diagnósticos de este tipo y que pueden conllevar a la creación y fortalecimiento de organizaciones para la reivindicación de derechos a partir de procesos de socialización, capacitación y formación. 
Es el caso de la creación de UTRASD, que en la actualidad logra un posicionamiento importante de la organización, de sus agendas y de sus lideresas en la agenda nacional e internacional, logrando cambios significativos en tan corto tiempo como lo fue la incidencia para la ley de primas de servicio, la creación de un espacio de diálogo permanente con el Ministerio de Trabajo y empleadores, así como la puesta en marcha de una plataforma intersindical para aunar fuerzas y trazar estrategias de forma conjunta.

\section{Referencias bibliográficas}

Arboleda, S. (2007). "Conocimientos ancestrales amenazados y destierro prolongado: la encrucijada de los afrocolombianos". En Claudia Mosquera y Luiz Barcelos (Eds), Afroreparaciones: Memorias de la esclavitud y justicia reparativa para negros, afrocolombianos y raizales (pp. 467-488). Bogotá, Colombia: Universidad Nacional de Colombia.

Arocha, J. (1998). "La inclusión de los afroscolombianos ¿meta inalcanzable? Geografía Humana", En Francois Correa (Ed), Geografía Humana de Colombia. Tomo VI Los afrocolombianos (pp. 334-390). Bogotá, Colombia: Instituto Colombiano de Cultura Hispánica. Recuperado de http://www.lablaa.org/blaavirtual/geog rafia/afro/inclusio.htm

Arocha, J. (2004). "Ley 70 de 1993: Utopía para Afro descendientes excluidos". En Jaime Arocha, (Comp), Utopía para los excluidos, el multiculturalismo en África y en América Latina (pp. 159178). Bogotá, Colombia: Universidad Nacional de Colombia.

Barbary, O., y Urrea, F. (Eds.). (2004). Gente negra en Colombia. Dinámicas sociopolíticas en Cali y el Pacífico. Medellín, Colombia: Institut de Recherche pour le Développement Universidad del Valle.

Bonilla, E., y Rodríguez, P. (2005). Más allá del dilema de los métodos: la investigación en ciencias sociales. Bogotá, Colombia: Norma.

Comisión Interamericana de Derechos Humanos (CIDH). (2011). La situación de las personas afrodescendientes en las Américas. Washington, Estados Unidos: Organización de los Estados Americanos. Recuperado de http://www.oas.org/es/cidh/afrodescen dientes/docs/pdf/AFROS_2011_ESP.p df

Corporación Convivamos. (2011). Condiciones de vida de la población negra, afrocolombiana, palenquera $y$ raizal en Medellín, caracterización demográfica, desarrollo humano $y$ derechos humanos 2010. Medellín, Colombia: Alcaldía de Medellín.

Correa, G., Pérez, A., Viveros, V., y Morales, M. (2011). Precario pero con trabajo: ¡otros están peor! Déficit de Trabajo Decente en la población afrocolombiana Cartagena, Buenaventura, Cali y Medellín 2009. 2010. Medellín, Colombia: Escuela Nacional Sindical.

El Tiempo. (2015). Lo que una líder de empleadas domésticas colombianas dijo en Harvard. Recuperado de https://www.eltiempo.com/archivo/do cumento/CMS-15734436

Escuela Nacional Sindical. (2016). Congreso aprobó ley de prima para trabajadorasdomésticas. Recuperado de http://ail.ens.org.co/mundo- 
sindical/congreso-aprobo-ley-primatrabajadoras-domesticas/

Galeano, M. (2004). Estrategias de investigación social cualitativa: el giro en la mirada. Medellín, Colombia: La Carreta.

Lao-Montes, A. (2007). "Sin justicia étnicoracial no hoy paz: las afro-reparaciones en perspectiva histórica mundial". En Claudia Mosquera y Luiz Barcelos (Eds), Afro-reparaciones: Memorias de la esclavitud y justicia reparativa para negros, afrocolombianos $y$ raizales (pp. 131-154). Bogotá, Colombia: Universidad Nacional de Colombia.

Lautier, B. (2003). "Las empleadas domésticas latinoamericanas y la sociología del trabajo: algunas observaciones sobre el caso brasileño". Revista mexicana de sociología, 65(4), 789-814.

Ministerio del Trabajo. (2017). Se evalúan avances de las políticas del sector de las trabajadoras domésticas. Recuperado de http://www.mintrabajo.gov.co/prensa/ comunicados/2017/octubre/seevaluan-avances-de-las-politicas-delsector-de-las-trabajadoras-domesticas

Pardo, M., Mosquera, C., y Ramírez, M. (2004). Panorámica afrocolombiana. Estudios sociales en el pacífico. Bogotá, Colombia: Instituto Colombiano de Antropología e Historia (ICANH), Universidad Nacional de Colombia.

Perfetti, M. (1996). "Diferenciales salariales entre hombres y mujeres noasalariadas durante el período 1984-1994". Revista Planeación y Desarrollo, 27(4), 67105.

Portilla, D. (2003). "Mercado laboral y discriminación racial: una aproximación para Cali”. Documento CEDE 2003-14 (59p.). Bogotá, Colombia: Universidad de los Andes.
Posso, J. (2008). La inserción laboral de las mujeres inmigrantes negras en el servicio doméstico de la ciudad de Cali. Madrid, España: Universidad Autónoma de Madrid.

República de Colombia. Corte Constitucional. (1998). Sentencia C-372 de 1998. Jornada laboral en cargos de dirección, de confianza y de manejo. Recuperado de https://www.corteconstitucional.gov.c o/relatoria/1998/C-372-98.htm

Romero, J. (2007). “¿Discriminación laboral o capital humano? Determinantes del ingreso laboral del afro cartageneros". Documentos de Trabajo sobre Economía Regional, $N^{o} 98$ (45p.). Cartagena de Indias, Colombia: Banco de la República.

Sistema de Identificación de Potenciales Beneficiarios de Programas Sociales. (s.f). ¿Qué es el Sisbén? Recuperado de https://www.sisben.gov.co/sisben/pagi nas/que-es.aspx

Tarrés, M. (Coord.). (2008). Observar, escuchar y comprender. Sobre la tradición cualitativa en investigación social. Ciudad de México, México: El Colegio de México - Facultad Latinoamericana de Ciencias Sociales.

Tenjo, J. (1992). "Labor Markets, the Wage Gap and Gender Discrimination: The Case of Colombia". En George Psacharopoulos y Zafiris Tzannatos (Eds.), Case studies on women's employment and pay in Latin America (pp. 149-169). Washington, Estados Unidos: World Bank.

Wade, P. (1987). "Raza y ciudad: los chocoanos en Medellín". Revista Antioqueña de Economía y Desarrollo, (23), 34-46.

Wade, P. (2008). "Población negra y la cuestión identitaria en América latina". Universitas humanística, (65), 117137. 